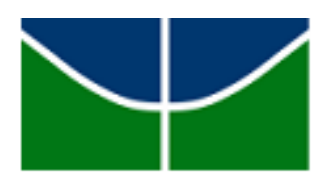

Universidade de Brasília - UnB

Faculdade de Ceilândia - FCE

Programa de Pós-Graduação em Ciências e Tecnologias em Saúde

TATIANE SOUSA DA SILVA

DOR COM CARACTERÍSTICAS NEUROPÁTICAS EM INDIVÍDUOS COM O DIAGNÓSTICO DE DIABETES MELLITUS TIPO 2 ATENDIDOS NA ATENÇÃO PRIMÁRIA.

BRASÍLIA 
TATIANE SOUSA DA SILVA

\section{DOR COM CARACTERÍSTICAS NEUROPÁTICAS EM INDIVÍDUOS COM O DIAGNÓSTICO DE DIABETES MELLITUS TIPO 2 ATENDIDOS NA ATENÇÃO PRIMÁRIA.}

Dissertação apresentada ao Programa de PósGraduação "Stricto Sensu" em Ciências e Tecnologias em Saúde da Universidade de Brasília, como requisito para a obtenção do Título de Mestre em Ciências e Tecnologias em Saúde.

Orientador (a): Prof. ${ }^{\text {a }}$ Dr. ${ }^{\text {a }}$ Mani Indiana Funez

Área de Concentração: Promoção, Prevenção e Intervenção em Saúde.

Linha de Pesquisa: Estratégias Interdisciplinares em Promoção, Prevenção e Intervenção em Saúde. 
Ficha catalográfica elaborada automaticamente, com os dados fornecidos pelo(a) autor(a)

Dor com características neuropáticas em indivíduos com o diagnóstico de diabetes mellitus tipo atendidos na Atenção Primária. / Tatiane Sousa da Silva; orientador Mani Indiana Funez. -- Brasilia, 2016.

$71 \mathrm{p}$.

Dissertação (Mestrado - Mestrado em Ciências e Tecnologias em Saúde) -- Universidade de Brasilia, 2016.

1. Neuropatia Diabética Periférica. 2. Dor Neuropática Diabética. 3. Atenção Primária. I. Funez, Mani Indiana, orient. II. Título. 


\section{DESCRIÇÃO DO PERFIL SÓCIO DEMOGRÁFICO, CARACTERIZAÇÃO E IDENTIFICAÇÃO DA DOR COM CARACTERÍSTICAS NEUROPÁTIÇAS EM INDIVÍDUOS COM O DIAGNÓSTICO DE DIABETES MELLITUS TIPO 2 ATENDIDOS NA ATENÇÃO PRIMÁRIA.}

Dissertação de Mestrado apresentada pela aluna Tatiane Sousa da Silva do Programa de PósGraduação em Ciências e Tecnologias em Saúde, tendo obtido o conceito de , conforme a apreciação da Banca Examinadora.

Aprovado em 28 de junho de 2016.

BANCA EXAMINADORA

Prof. ${ }^{\mathrm{a}}$ Dr ${ }^{\mathrm{a}}$ Mani Indiana Funez

Orientadora

Paulo Gustavo Barboni Dantas Nascimento

Membro Examinador

Marina Morato Stival

Membro Examinador

Silvana Schwerz Funghetto

Membro Suplente

Brasília 


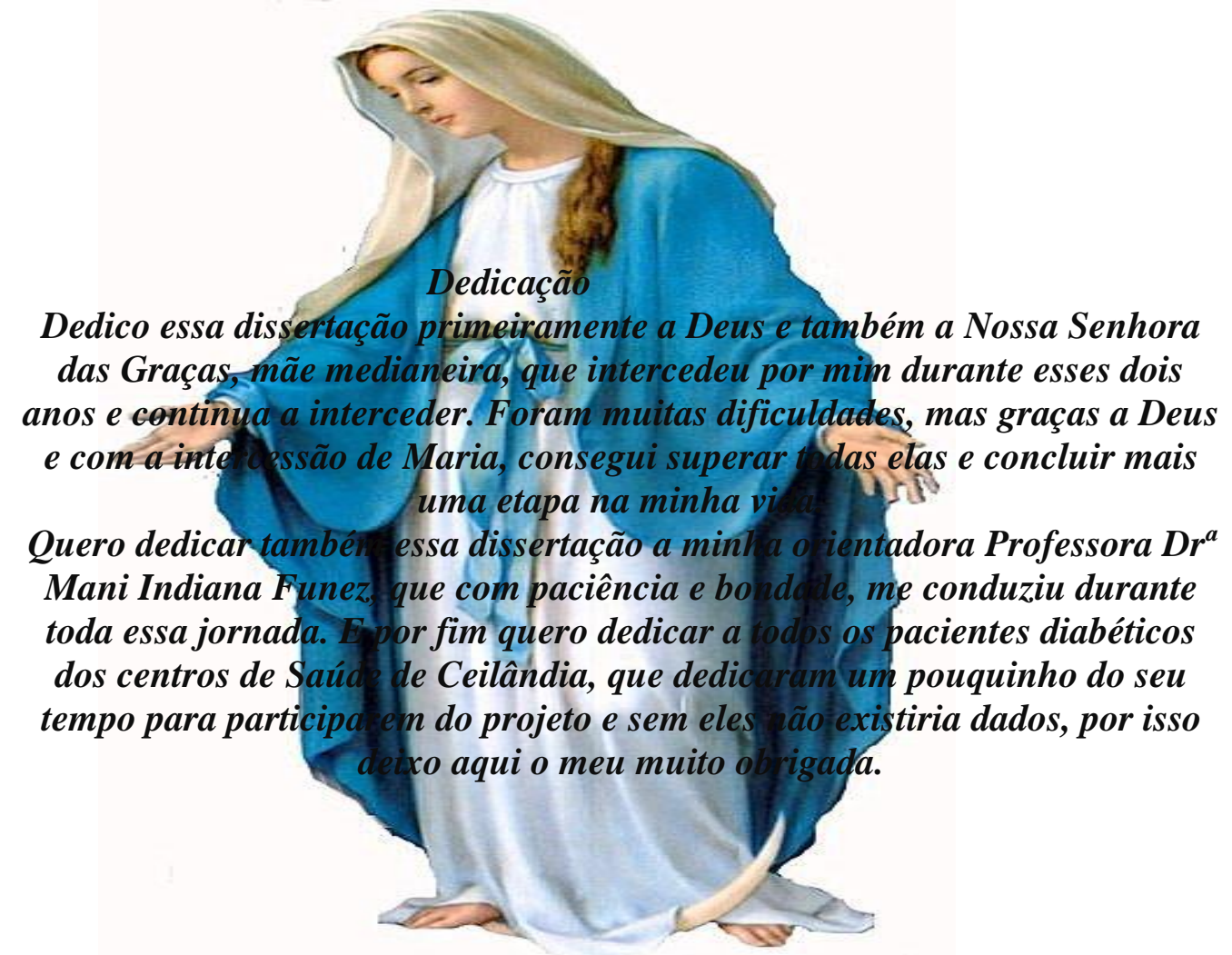




\section{AGRADECIMENTOS}

A Deus por ter me dado o dom da vida, a oportunidade de continuar com meus sonhos, por ter me abençoado com muitas graças e por ter me ajudado a finalizar o meu trabalho.

Ao meu pai, minha mãe, minha irmã, sobrinha e amigos pela paciência, ajuda e por ter compreendido minha ausência.

Aos pacientes diabéticos que participaram dessa pesquisa e permitiram a finalização desse trabalho.

À professora $\operatorname{Dr}^{a}$ Mani Indiana Funez pelo exemplo de dedicação, de profissional, de professora, de amor ao trabalho, ao próximo, mesmo diante de dificuldades, e pela paciência e carinho comigo.

Às alunas de Iniciação: Amanda de Araújo Fonseca e Sammya Rodrigues dos Santos, pela paciência e auxilio na coleta.

Às minhas novas amigas e companheiras de coleta: Priscila da Conceição Quaresma e Paula Muniz Machado, pela ajuda, paciência, amizade, parceria e apoio nos momentos de coleta e pessoais. Sem vocês o trabalho não teria sido maravilhoso.

A todos os funcionários dos Centros de Saúde que a coleta foi desenvolvida, pelo acolhimento e ajuda.

À Coordenação de Aperfeiçoamento de Pessoal de Nível Superior - Capes e ao Programa de Demanda Social do Decanato de Pesquisa e Pós-graduação DPP- UnB, por terem me concedido a bolsa que me ajudou a continuar na pesquisa.

Ao Programa de Pesquisa para o SUS - PPSUS do Ministério da Saúde, por ter financiado esse estudo.

Aos membros da banca examinadora que aceitaram participar e contribuir para as melhorias deste trabalho.

À Secretaria da Pós-graduação pelo empenho nas atividades prestadas. 
A todos que direta ou indiretamente colaboraram com a elaboração desta dissertação. 
SUMÁRIO

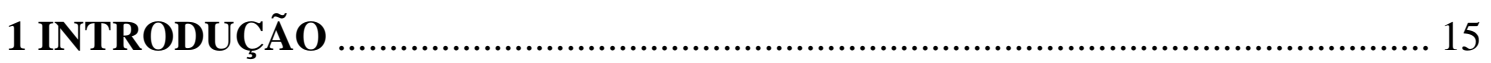

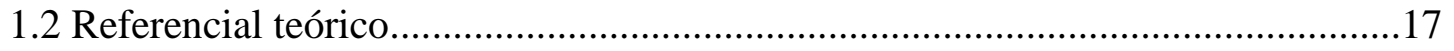

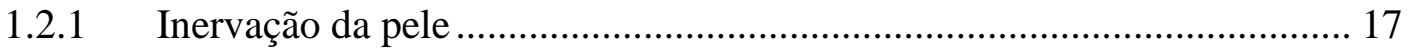

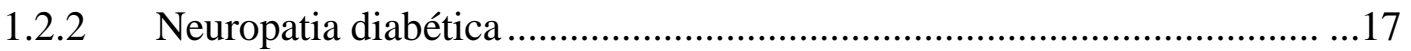

1.2.3 Dor Neuropática Diabética ................................................................. 21

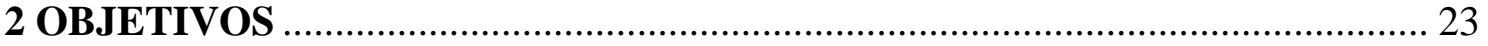

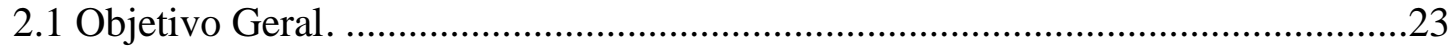

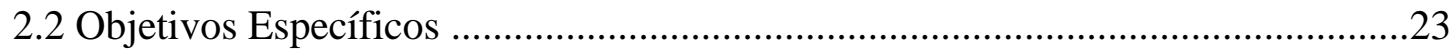

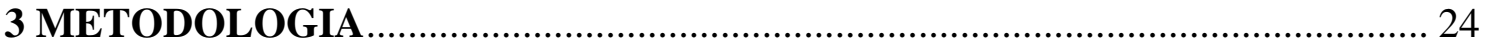

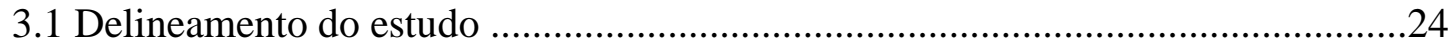

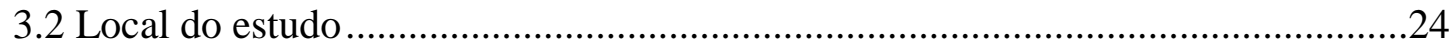

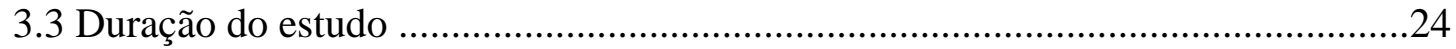

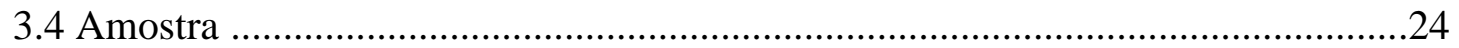

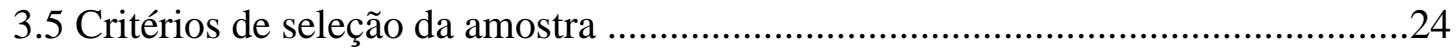

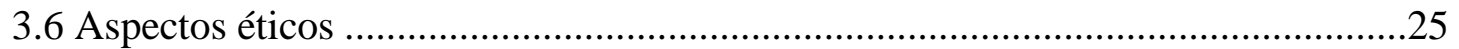

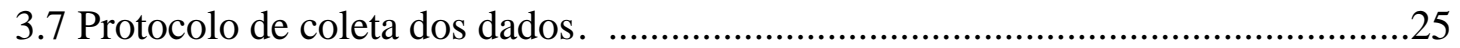

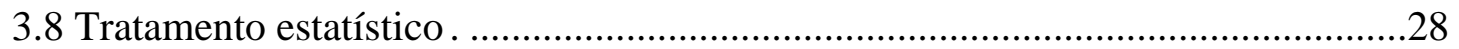

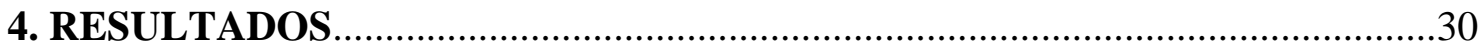

4.1. Caracterização sócio demográfica ….................................................................30

4.2. Presença ou ausência de dor .. .........................................................................33

4.3. Estratégias de enfrentamento da dor com características neuropática ..................35

4.4 Caracterização da dor com características neuropáticas ........................................39

4.5 Glicemia e tempo do diagnóstico de diabetes mellitus .........................................42

4.6. Identificação da dor com características neuropáticas - descrição e exame da função

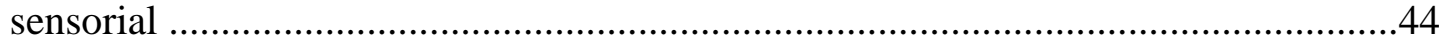

5 DISCUSSÃ

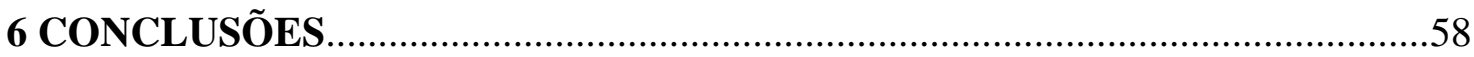

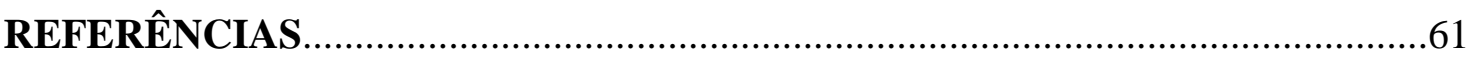




\section{LISTA DE TABELAS}

Tabela 1 - Resumo dos testes e tipos de estímulos em distintas fibras sensoriais

Tabela 2 - Perfil sócio demográfico dos pacientes com diagnóstico de diabetes mellitus tipo 2 atendidos na atenção primária em Ceilândia. Ceilândia, DF, 2016

Tabela 3 - Estratégias para o enfrentamento da dor dos pacientes com diagnóstico de diabetes mellitus tipo 2 atendidos na atenção primária em Ceilândia. Ceilândia, DF, 2016

Tabela 4 - Outras estratégias para o enfrentamento da dor dos pacientes com diagnóstico de diabetes mellitus tipo 2 atendidos na atenção primária em Ceilândia. Ceilândia, DF, 2016 .......

Tabela 5 - Caracterização da dor nos pés e/ou panturrilhas dos pacientes com diagnóstico de diabetes mellitus tipo 2 atendidos na atenção primária em Ceilândia. Ceilândia, DF, 2016

Tabela 6 - Comparação entre as características da dor nos pés e/ou panturrilhas relatadas pelos pacientes com diagnóstico de diabetes mellitus tipo 2 atendidos na atenção primária em Ceilândia. Ceilândia, DF, 2016

Tabela 7 - Valor da glicemia e tipo de glicemia dos pacientes com diagnóstico de diabetes mellitus tipo 2 atendidos na atenção primária em Ceilândia. Ceilândia, DF, 2016

Tabela 8 - Frequência absoluta e relativa do tempo de diabetes dos pacientes com diagnóstico de diabetes mellitus tipo 2 atendidos na atenção primária em Ceilândia. Ceilândia, DF, 2016

Tabela 9 - Frequência cruzada entre o tempo de dor e a glicemia dentro ou não dos padrões de normalidade; e entre o tempo de dor e o total das glicemias dos pacientes com diagnóstico de diabetes tipo 2 atendidos na atenção primária em Ceilândia. Ceilândia, DF, 2016

Tabela 10 - Descrição e exame da função Sensorial da dor nos pés e/ou panturrilhas dos pacientes com diagnóstico de diabetes tipo 2 atendidos na Atenção Básica em Ceilândia. Ceilândia, DF, 2016

Tabela 11 - Média, mediana e desvio padrão dos valores da escala LANNS por classificação

LANNS. Ceilândia, DF, 2016

Tabela 12 - Escore total da Escala de dor LANNS segundo a Escala de dor LANNS nos 
pacientes com diagnóstico de diabetes mellitus tipo 2 com dor nos pés e/ou panturrilhas atendidos na Atenção Básica em Ceilândia. Ceilândia, DF, 2016

Tabela 13 - Frequência cruzada entre resultados dos testes e Escore de dor LANNS. Ceilândia, DF, 2016 .50

Tabela 14 - Tabela 14 - Frequência cruzada entre tempo de diabetes e escore LANNS e PSP. Ceilândia, DF, 2016 51 


\section{FIGURAS, APÊNDICES E ANEXOS}

Figura 1 - Locais de Aplicação do Monofilamento de $10 \mathrm{~g}$

Figura 2 - Presença ou ausência de dor nos pacientes com diagnóstico de diabetes mellitus tipo 2 atendidos na atenção primária em Ceilândia. Ceilândia, DF, 2016

Figura 3 - Locais de dor nos pacientes com diagnóstico de diabetes mellitus tipo 2 atendidos na atenção primária em Ceilândia. Ceilândia, DF, 2016 .34

Figura 4 - Dor nos pés e/ou panturrilhas nos pacientes com diagnóstico de diabetes mellitus tipo 2 atendidos na atenção primária em Ceilândia. Ceilândia, DF, 2016 .35

Figura 5 - Valores de glicemia capilar apresentados por pacientes com diagnóstico de diabetes mellitus tipo 2 atendidos na atenção primária que tem dor nos pés e/ou panturrilhas. Ceilândia, DF, 2016 43

Apêndice 1 - Tabela para determinação do tamanho amostral por erro de estimação de proporções... . .66

Apêndice 2 - Termo de Consentimento Livre e Esclarecido .67

Anexo 1 - Aprovação do Comitê de Ética e Pesquisa com Seres Humanos .68

Anexo 2 - Escala de dor LANNS . .69 


\section{SÍMBOLOS, SIGLAS E ABREVIATURAS}

ND Neuropatia Diabética

DM 2 Diabetes Mellitus tipo 2

IASP Associação Internacional de Estudo da Dor.

TCLE Termo de Consentimento Livre e Esclarecido

PSP Perda da Sensibilidade Protetora plantar.

QST Teste Sensorial Quantitativo

FEPECS Fundação de Ensino e Pesquisa em Ciências da Saúde

EVA Escala Visual Analógica

IMC Índice de Massa Corpórea

SES-DF Secretaria de Estado de Saúde do Distrito Federal

UNB Universidade de Brasília

FCE Faculdade de Ceilândia

ADA American Diabetes Association

PDAD Pesquisa distrital por amostra de domicílios 


\section{RESUMO}

Introdução: Neuropatia Diabética Periférica (ND) é a complicação mais comum do diabetes mellitus, pode vir acompanhada de dor neuropática, que afeta até 50\% dos pacientes. A dor neuropática é definida como dor que surge como consequência direta de uma lesão que afeta o sistema somatossensorial em pacientes com diagnóstico de diabetes. No Brasil não existem estudos populacionais realizados na atenção primária que caracterizam e identificam ND e dor neuropática. Nesse contexto, o objetivo deste estudo foi identificar dor com características neuropáticas em indivíduos com o diagnóstico de diabetes mellitus tipo 2 atendidos na atenção primária. Método: Trata-se de um estudo transversal, prospectivo, quantitativo, realizado no Distrito Federal, Brasil, com uma amostra de 237 pacientes com DM2, divido em 3 etapas: atendimento aos critérios da pesquisa e dados sócio demográficos; caracterização da dor com características neuropáticas, estratégias de enfrentamento da dor e verificação da glicemia; e identificação da dor com características de neuropatia - exames de função sensorial e escala de dor LANNS. Resultados: A população é composta em sua maioria por pessoas do sexo feminino, de cor/etnia parda, estado civil casado, escolaridade ensino fundamental, com média da idade de $51 \pm 6$ anos, renda familiar média mensal de $\mathrm{R} \$ 2225,74 \pm 1572,80$ e renda per capita média de $\mathrm{R} \$ 675,67 \pm 492,70$. Cerca de $94 \%$ dos pacientes referiram dor nos pés e/ou panturrilhas e houve diferença estatística ( $\mathrm{p}<0,000)$ entre esse e o grupo de pessoas que não sentiam dor. A intensidade da dor foi de moderada a intensa, a maioria sente dor durante a noite ou dia e noite. As características mais relatadas foram: fadiga, câimbras, queimação, formigamento, dormência, alfineta e/ou agulhada. Em relação aos testes de função sensorial $78 \%$ foi descartada perda da sensibilidade protetora plantar. Cerca de $87,5 \%$ apresentou dor no qual possíveis mecanismos neuropáticos não estariam contribuindo para a dor do paciente. Conclusão: A maioria dos pacientes não tem dor com possíveis mecanismos neuropáticos de acordo com a escala de dor LANNS, porém apresenta dor com características neuropáticas. $\mathrm{O}$ processo inflamatório sistêmico provocado pela hiperglicemia, resistência à insulina, perda da sinalização da insulina e/ou dislipidemia pode ser o que está contribuindo para a dor desses pacientes que não foram identificados com dor neuropática pela escala de dor LANNS.

Palavras Chaves: Neuropatia Diabética Periférica; Dor Neuropática Diabética; Atenção Primária. 


\begin{abstract}
Introduction: Diabetic peripheral neuropathy (DPN) is the most common complication of diabetes mellitus, can be accompanied by neuropathic pain, which affects up to $50 \%$ of patients. Neuropathic pain is defined as pain arising as a direct result of an injury that affects the somatosensory system in patients with diabetes. In Brazil there are no population studies conducted in primary care that characterize and identify ND and neuropathic pain. In this context, the aim of this study was to identify pain with neuropathic characteristics in individuals diagnosed with type 2 diabetes mellitus in primary care. Method: This is a cross-sectional, prospective, quantitative, held in the Federal District, Brazil, with a sample of 237 patients with DM2, divided into 3 stages: meeting the search criteria and socio-demographic data; characterization of pain with neuropathic characteristics, coping strategies pain and verification of blood glucose; and identification of pain with neuropathy characteristics - examinations of sensory function and LANNS pain scale. Results: The population consists mostly of females, color / brown ethnicity, married marital status, primary school education, with a mean age of $51 \pm 6$ years, average monthly household income of $\mathrm{R} \$ 2,225.74 \pm 157280$ and average per capita income of $\mathrm{R} \$ 675.67 \pm 492.70$. About $94 \%$ of patients reported pain in the feet and / or calves and was no statistical difference $(\mathrm{p}<0.000)$ between this and the group of people who felt no pain. The intensity of pain was moderate to intense; most feel pain during the night or day and night. The most frequently reported characteristics were fatigue, cramps, burning, tingling, numbness, teases and / or needled. Regarding sensory function tests $78 \%$ was discarded loss of protective sensation plant. About $87.5 \%$ had pain where possible neuropathic mechanisms would not be contributing to the patient's pain. Conclusion: Most patients have no pain with possible neuropathic mechanisms according to LANNS pain scale, but has pain with neuropathic characteristics. Systemic inflammation caused by hyperglycemia, insulin resistance, loss of insulin signaling and / or dyslipidemia may be what is contributing to the pain of those patients who were identified with neuropathic pain by LANNS pain scale.
\end{abstract}

Key words: Diabetic Neuropathy Peripheral; Diabetic Neuropathic Pain; Primary attention. 


\section{INTRODUÇÃO}

A neuropatia diabética periférica (ND) pode ser definida como: "presença de sinais e/ou sintomas de disfunção do nervo periférico em pessoas com o diagnóstico de diabetes mellitus após a exclusão de outras causas" ${ }^{1}$.

A ND é a complicação mais comum do diabetes mellitus tipo 2 (DM2) e tem uma prevalência estimada em torno de 45-50\% em comparação com 25-30\% da retinopatia e 20\% da nefropatia² ${ }^{2}$ É também o principal fator inicial de ulceração do pé, da neuroartropatia de Charcot e amputação das extremidades inferiores ocasionando a incapacidade dos pacientes 3 .

No entanto, a qualidade e a quantidade de dados epidemiológicos sobre a ND sintomática continuam pobres devido a definições inconsistentes, má apuração e falta de estudos populacionais ${ }^{3}$. No Brasil não existe estudo populacional realizado na atenção primária que estime a prevalência e incidência da ND na população com diagnóstico de diabetes. A prevalência da ND no geral é estimada em cerca de $8 \%$ em pacientes com o diagnóstico recente de diabetes e maior do que $50 \%$ em pacientes com longa duração da doença ${ }^{4,5}$.

O principal fator de risco para ND é a hiperglicemia. Outros fatores de risco independentes incluem: idade, duração da doença, tabagismo, hipertensão arterial, triglicerídeos elevados, IMC elevado, consumo de álcool entre outros ${ }^{4}$.

$\mathrm{O}$ reconhecimento precoce e o tratamento adequado da neuropatia no paciente com diabetes são importantes por uma série de razões: as neuropatias não diabéticas podem estar presentes em pacientes diabéticos; várias opções de tratamento existem para a neuropatia diabética sintomática; até $50 \%$ das neuropatias podem ser assintomáticas, esses pacientes estão em risco de lesão nos pés devido à falta de sensibilidade, sendo que $80 \%$ das amputações de membros inferiores são precedidas de úlceras e lesões nos pés e o reconhecimento precoce da situação de risco desses pacientes auxiliam na educação e orientações de cuidados com os pés adequados a esse paciente, reduzindo a incidência de ulceração e, consequentemente, a amputação'.

A ND ainda pode ser apresentada com sintomas dolorosos. A dor neuropática pode ser definida segundo a Associação Internacional de Estudo da dor como: "dor que surge como consequência direta de uma lesão que afeta o sistema somatossensorial em pacientes com diagnóstico de diabetes". A diabetes é a causa mais frequente das neuropatias dolorosas e 1/3 dos pacientes com polineuropatia sensório-motora diabética, principal forma da neuropatia diabética, sofre de dor neuropática. A ND dolorosa tem um impacto negativo sobre a qualidade de vida física e mental, em comparação com a ND não dolorosa ${ }^{6}$. 
Embora a prevalência e os fatores de riscos da ND tenham sido objetos de estudos principalmente internacionais, há poucos estudos que apresentam especificamente a prevalência da dor neuropática. Os estudos existentes mostram que a prevalência varia de $10 \mathrm{a}$ $26 \%$. Um estudo realizado no Reino Unido mostrou uma prevalência de 34\% de ND dolorosa e um estudo realizado na Arábia Saudita mostrou a prevalência de 65,3\% de ND dolorosa na população ${ }^{3,7}$.

Até $50 \%$ dos pacientes com ND pode experimentar sintomas dolorosos, embora muitos dos pacientes não terão dor de gravidade suficiente para justificar o tratamento. De todos os sintomas da ND a dor é a razão mais importante e mais frequente para a procura do atendimento médico 5 .

$\mathrm{O}$ atendimento inicial do paciente diabético ocorre na atenção primária, onde há o rastreamento da doença, consultas médicas e de enfermagem com foco na promoção, prevenção, detecção de casos, monitoramento, controle da glicemia e início das ações de educação em saúde voltadas para prevenção de complicações e para a manutenção da qualidade de vida. O Ministério da Saúde prevê todo o acompanhamento do paciente com diagnóstico de diabetes mellitus na unidade básica de saúde (UBS). As complicações são primeiramente identificadas nesse nível de atenção e quando há necessidade de tecnologias diagnósticas e para o tratamento mais específicas, há o encaminhamento para o tratamento a nível hospitalar, com a continuidade do acompanhamento também nas unidades básicas de saúde ${ }^{8}$.

O principal papel da atenção primária, no que se refere aos cuidados do paciente já com o diagnóstico de diabetes é a prevenção das possíveis complicações da doença, sendo que o controle glicêmico ainda é considerado um dos principais tratamentos que diminui as possíveis complicações que a doença pode ocasionar.

O rastreamento da ND tanto dolorosa, quanto não dolorosa é realizado na atenção primária nas consultas médicas e de enfermagem, onde esses profissionais devem incluir em suas rotinas diárias o exame dos pés ${ }^{8}$.

No Brasil não existem estudos populacionais realizados na atenção primária que caracterizem e identifiquem ND e dor neuropática. As pesquisas que tem como objeto de estudo a ND ou a dor neuropática foram realizadas em ambulatórios de grandes hospitais, onde o principal viés desses estudos são os próprios pacientes atendidos que já possuem complicações na maioria dos casos. Diferentemente espera-se que pelo menos a maioria dos pacientes atendidos na atenção primária ainda não tenham complicações, mas que ao longo do diagnóstico da doença e na falta do controle glicêmico possam desenvolver. Com base nessa falta de informações da realidade brasileira na atenção primária é que o presente estudo propõe 
caracterizar e identificar dor com características neuropáticas em pacientes com diagnóstico de diabetes mellitus tipo 2 atendidos na atenção primária.

A identificação precoce dos casos possibilita o tratamento adequado e imediato, prevenindo o desfecho de complicações mais graves como o pé diabético. Sendo, portanto, a principal contribuição do estudo a identificação precoce dos casos de ND e dor com características neuropáticas, antes mesmo das lesões que caracterizam o pé diabético.

\subsection{Referencial teórico}

\subsubsection{Inervação da pele}

Os principais neurônios afetados na ND são os neurônios sensoriais. Esses neurônios são um grupo heterogêneo que transmitem diferentes tipos de informações e são classificados de modo geral pelo diâmetro do corpo da célula: pequeno (20 $\mu \mathrm{m}$ - chamados fibras $\mathrm{C})$, médio (21-40 $\mu \mathrm{m}$ - denominado A- $\delta$ ) e grande (> $40 \mu \mathrm{m}$, chamado A- $\alpha$ e A- $\beta)^{9}$.

As fibras nervosas epidérmicas são nervos que existem nas camadas mais externas da pele, a epiderme, e são frequentemente afetados pela ND. As fibras nervosas epidérmicas compreendem as fibras $\mathrm{C}$ e fibras $\mathrm{A}-\delta$. As fibras $\mathrm{C}$ são não-mielinizadas e estão envolvidas na nocicepção e calor. Fibras A- $\delta$ são levemente mielinizadas e são fibras mecanoreceptoras. As fibras A- $\alpha$ e A- $\beta$ são fortemente mielinizadas e são fibras condutoras rápidas proprioceptivas ${ }^{9}$.

A proporção da perda de fibras nervosas epidérmicas sozinhas, nem sempre se correlaciona com a gravidade da neuropatia ou sua extensão. No entanto, uma perda de fibras nervosas epidérmicas na pele combinada com espessamento dos axônios correlaciona-se com a gravidade da neuropatia dolorosa nos pés induzida pelo diabetes, por exemplo 9 .

Existem várias causas de neuropatia sensorial dolorosa. Em um subtipo denominado de neuropatia dolorosa de pequenas fibras sensoriais, apenas as fibras A- $\delta$ e nociceptiva $C$ são afetadas. Em outro grupo de neuropatias associadas com a dor, o desconforto é causado em parte pelo dano das pequenas fibras nervosas, mas também a grandes fibras nervosas (A- $\alpha$ e A$\beta)$ que são responsáveis pela propriocepção, sensação vibratória, reflexos de estiramento muscular e força muscular também são $\operatorname{afetados}^{10}$.

\subsubsection{Neuropatia diabética}


A ND acomete os neurônios sensoriais e motores. Ela pode ser heterogênea, afetando diferentes partes do sistema nervoso e se apresentando com diversas manifestações clínicas. Ela ainda pode ser aguda ou sensório-motora crônica ${ }^{1,5}$.

A neuropatia sensorial aguda é rara e tende a acompanhar períodos de mau controle metabólico ou súbita mudança no controle da glicemia, ou seja, ela pode ocorrer no momento que os pacientes apresentam hiperglicemia. Ela é caracterizada pelo início agudo dos sintomas sensoriais graves, com exacerbação noturna, marcados por alguns sinais neurológicos no exame dos membros inferiores. Com a normalização da glicemia, os sinais e sintomas tendem a desaparecer ${ }^{1}$.

A neuropatia sensório-motora crônica é a forma mais comum de ND e até $50 \%$ dos pacientes podem apresentar sintomas dolorosos, sendo os descritores de dor mais frequentes: dor em queimação, choques elétricos, facada, parestesia, hiperestesia e dor profunda. Essa dor piora a noite e os sintomas são mais comumente experimentados nos pés e membros inferiores ${ }^{1}$. Essa forma de ND ocorre independentemente das mudanças no controle da glicemia, pois nesse estágio o mau controle glicêmico já provocou lesões irreversíveis nos neurônios, levando ao aparecimento dos sinais e sintomas.

O estudo da neuropatia aguda não foi objetivo deste trabalho, para tanto foram excluídos os pacientes que apresentavam glicemia fora dos padrões toleráveis. Também não foi alvo de investigação a neuropatia autonômica, desta forma, ao utilizarmos o termo ND estaremos nos referindo à Neuropatia Diabética Sensório-Motora Crônica.

A ND ainda pode ter definições de critérios e são eles:

- ND possível - presença de sinais e sintomas que podem incluir: sintomas de sensações diminuídas, sintomas sensoriais neuropáticos positivos (dormência, sensação de agulhada ou facada, queimação ou dores) predominantemente nos dedos dos pés, pés ou pernas; ou diminuição da sensação de sinais simétricos distais ou diminuição ou ausência dos reflexos aquileus ${ }^{11}$.

- ND provável - presença da combinação de sinais e sintomas de neuropatia que incluem: sintomas neuropáticos, diminuição da sensibilidade distal ou diminuição ou ausência dos reflexos de aquileu ${ }^{11}$.

- ND confirmada - presença de anormalidade na condução nervosa e um sintoma (s) ou um sinal (is) de ND. Se a condução nervosa for normal, pode-se utilizar uma medida validada de neuropatia de fibra pequena ${ }^{11}$.

- ND subclínicas - presença de sinais ou sintomas de neuropatia são confirmadas com a condução nervosa anormal ou uma medida validada de neuropatia de fibras pequenas ${ }^{11}$. 
A patogênese da ND é objeto de investigação por ser uma doença (CID: G632) multifatorial. É o resultado de várias perturbações bioquímicas. A hiperglicemia crônica parece ser a principal responsável pelo início de vários eventos metabólicos subjacentes a ND. Combinação de lesão direta dos axônios devido as consequências metabólicas da hiperglicemia, resistência à insulina, adiposidade toxica, lesão endotelial e disfunções microvasculares levam a isquemia do nervo. Vários mecanismos patogênicos envolvidos no curso clínico da doença podem afetar a estrutura e a função do nervo. No decurso do início de diabetes a ativação da via do poliol, com uma consequente diminuição neural na atividade $\mathrm{Na}^{+} / \mathrm{K}^{+}$-ATPase, leva ao comprometimento do fluxo sanguíneo endoneural e microvascular e à reatividade macrovascular. A hipoxemia endoneural secundária ao fluxo sanguíneo endoneural prejudicado contribui para uma perfusão prejudicada no nervo e após isso a disfunção do nervo. Uma das primeiras mudanças estruturais detectáveis em fibras mielinizadas é o aumento no volume axonal nodal e paranodal que está associado a outras anomalias da estrutura do citoesqueleto levando a perturbação do transporte axonal e atrofia axonal progressiva. Anomalias funcionais como o retardo da velocidade de condução do nervo sensorial e velocidade de condução nervosa motora, hiperalgesia e alodinia podem ser desenvolvidas e encontradas nos primeiros meses do início da hiperglicemia. À medida que a doença progride, os sinais de axonopatia, desmielinização, degeneração nervosa e hipoalgesia podem ser detectados. Hiperalgesia térmica aparece progressivamente durante o curso da doença quando as pequenas fibras $\mathrm{C}$ e A$\delta$ não mielinizadas estão prejudicadas e finalmente resulta na perda profunda das fibras $\mathrm{C}^{12}$.

A patologia da ND é caracterizada pela perda progressiva de fibras nervosas com padrão de tamanho das fibras, a degeneração das fibras do nervo é dependente do notável comprimento e em parte distal. As fibras pequenas são preferencialmente afetadas em estágios iniciais, seguida pelo envolvimento de grandes fibras relacionadas com a redução da velocidade de condução do nervo ou diminuição do limiar de vibração. Sendo assim, os sinais e sintomas são baseados em alterações estruturais ${ }^{2}$.

Estudos têm demonstrado que a inflamação pode ser um fator importante que está contribuindo para os danos nas fibras nervosas periféricas ${ }^{13}{ }^{14,15}$. A hiperglicemia juntamente com a perda da sinalização da insulina e resistência à insulina juntamente com a desregulação do metabolismo lipídico e dislipidemia, levam a inflamação sistêmica e ciclos viciosos de estresse oxidativo/nitrosativo, estresse endoplasmático e mitocondrial que vão gerar a acumulação de danos celulares. Glicotoxicidade, insulopenia e lipotoxicidade produzem estresse oxidativo neuronal e nitrosativo e ativam múltiplas proteínas quinases e fatores de transcrição. Esses fatores vão desempenhar um papel crítico desencadeando uma cascata de 
citocinas e a produção de quimiocinas que não só contribuem para o processo inflamatório existente e respostas imunes, como também contribuem para o estresse oxidativo e nitrosativo promovendo ainda mais danos neuronais ${ }^{16}$.

Os sinais e sintomas de ND variam dependendo do tipo de fibra envolvida, quan do há o envolvimento de fibras de grande diâmetro há prejuízo da propriocepção e toque leve. Quando há o envolvimento de fibras de pequeno diâmetro há prejuízo da dor e da percepção da temperatura, levando a parestesia, disestesia e / ou dor neuropática. Fraqueza distal ocorre apenas nos casos mais graves. Reflexos profundos do tendão diminuídos ou ausentes, particularmente o reflexo do tendão de Aquiles, muitas vezes indicam ND leve e assintomática ${ }^{4}$.

Os sintomas podem ser divididos em sintomas positivos, onde os pacientes sentem sensações desconfortáveis e se queixam de dor e sintomas negativos onde pode não haver nenhuma queixa dos pacientes ${ }^{2}$.

A recomendação para o rastreamento de ND é um exame clínico cuidadoso, onde todos os pacientes devem ser rastreados para ND anualmente realizando um ou mais dos seguintes exames para avaliar a função sensorial: sensação de picada (teste do palito), temperatura, percepção de vibração (usando diapasão de $128 \mathrm{~Hz}$ ), monofilamento de $10 \mathrm{~g}$ para a sensação de pressão e reflexos do tornozelo. Combinações de mais de um teste tem valores $>87 \%$ de sensibilidade na detecção de $\mathrm{ND}^{1,17,18}$.

O exame do membro inferior geralmente revela perda sensorial de vibração, pressão, dor e percepção da temperatura (mediada por fibras pequenas e grandes) e reflexos dos tornozelos ausentes. Portanto, é importante realizar anualmente o rastreamento da ND examinando sensação de picada, temperatura, percepção de vibração usando diapasão de 128 $\mathrm{Hz}$ e sensação de pressão usando o monofilamento de $10 \mathrm{~g}^{1,7}$.

A suspeita de ND se dá quando sintomas subjetivos como dor em queimação, parestesia, hiperestesia e câimbras dolorosas envolvendo preferencialmente os membros inferiores são referidos pelos pacientes e/ou quando a diminuição da vibração (diapasão $128 \mathrm{~Hz}$ ) e sensação tátil (monofilamento $10 \mathrm{~g}$ ) e/ou distúrbios de percepção térmica e reflexo de Aquileu ausentes são observados ${ }^{7}$.

A Tabela 1 mostra o resumo das informações dos tipos de estímulos em distintas fibras sensoriais periféricas e relevância clínica para as condições de dor. 
Tabela 1 - Resumo dos testes e tipos de estímulos em distintas fibras sensoriais.

\begin{tabular}{lcc}
\hline \multicolumn{1}{c}{ Testes } & $\begin{array}{c}\text { Sensação fisiológica } \\
\text { elucidada }\end{array}$ & Tipo de Fibra Testada \\
\hline $\begin{array}{l}\text { Sensação de pressão (Monofilamento) } \\
\text { Sensação Vibratória (diapasão) }\end{array}$ & Toque & A- $\beta$ \\
$\begin{array}{l}\text { Sensibilidade dolorosa profunda } \\
\text { (sensação de picada) }\end{array}$ & Picada, dor aguda & A- $\beta$ \\
$\begin{array}{l}\text { Sensibilidade a temperatura (frio) } \\
\text { Alodinia }\end{array}$ & Frio $\delta$ e C \\
$\begin{array}{l}\text { Alteração do limiar por estímulo de } \\
\text { agulha }\end{array}$ & Ticada, dor aguda & A- $\delta$ e C \\
\end{tabular}

Fonte: Backonja MM, Attal N, Baron R, Bouhassira D, Drangholt M, Dyck PJ et al (2013) e International Association for the Study of Pain (2015) ${ }^{19,20}$.

\subsubsection{Dor Neuropática Diabética}

A dor e perda da função estão associadas com a reação de danos ao sistema nervoso. A dor neuropática periférica é o resultado de lesões do sistema nervoso periférico, causada por trauma mecânico, doenças metabólicas, produtos químicos, neurotóxicos, infecção ou invasão tumoral e envolve várias alterações fisiopatológicas tanto no sistema nervoso periférico, quanto do sistema nervoso central. Estudos epidemiológicos sobre a prevalência neuropática indicam uma incidência de aproximadamente $5 \%$. Os fatores de riscos associados incluem: sexo, idade e localização anatômica da lesão ${ }^{21}$.

Os sintomas de dor neuropática em pacientes diabéticos muitas vezes são difíceis de serem descritos, os descritores mais comuns incluem: dor ardente, choques elétricos, dor tipo tiro abaixo das pernas, lancinante (comparada a facadas), formigamento desconfortável (parestesia) e dor de contato provocada por tocar meias durante o dia ou meias ou roupas de cama à noite (alodinia). Desconforto no pé também pode ser descrito como "andar descalço no mármore" ou "andar descalço na areia quente". Sensações subjetivas de percepção de temperatura alteradas, como os pés muito quentes ou muito frios, também são comuns, mas não-específica para sensações dolorosas nos pés ${ }^{22}$.

A dor neuropática em pacientes com DM é caracteristicamente mais intensa à noite, muitas vezes resultando em distúrbios do sono, com pacientes gravemente afetados que se queixam de estarem constantemente cansados por causa da grave privação de sono. Juntamente 
com os sintomas dolorosos durante o dia, isso muitas vezes leva a uma redução da capacidade dos indivíduos em realizar atividades diárias. O alívio da dor melhora o sono; e o grau de perda de sono prevê a resposta a analgésicos. A dor neuropática nos pacientes diabéticos persistentemente (ou crônica) pode ser extremamente angustiante e pode estar associada com a depressão profunda, juntamente com a ansiedade e perda de sono. Com relação à história natural da ND dolorosa, há poucos estudos, mas acredita-se que os sintomas dolorosos podem aumentar e diminuir ao longo dos anos e, eventualmente, tornar-se menos proeminentes com a piora da perda sensorial ${ }^{22}$.

Diversos mecanismos fisiopatológicos tem sido elucidados para explicar a dor neuropática em pacientes diabéticos. Os mecanismos periféricos envolvidos provavelmente envolvidos na dor neuropática diabética são: alterações na distribuição e expressão de canais de sódio e cálcio; sensibilização periférica; fluxo sanguíneo periférico alterado; atrofia, degeneração ou regeneração dos axônios e danos as pequenas fibras ${ }^{22}$.

O manejo da dor neuropática é um desafio, e muitos pacientes não obtêm nenhum alívio da dor ou obtêm apenas alívio parcial quando tomam os medicamentos atualmente disponíveis para a dor. Devido às limitações dos tratamentos atuais a dor neuropática é considerada ainda uma necessidade clínica não satisfeita ${ }^{23}$.

Na última década houveram avanços significativos no desenvolvimento de técnicas que definem o fenótipo somatossensorial no contexto da dor neuropática. Estão incluídos nessas técnicas questionários como: DN4, painDETECT e escala de dor Leeds Assessment of Neuropathic Symptoms and Signs (LANNS). O objetivo desses questionários é distinguir a dor neuropática de outros tipos de dor, ou seja, identificar a dor no qual possíveis mecanismos neuropáticos estariam envolvidos, por meio de descritores de dor relatados pelos pacientes e padronização do teste sensorial quantitativo (QST). O QST avalia a percepção sensorial em resposta a um estímulo sensorial definido. Esses testes podem ser utilizados para testar uma variedade de modalidades sensoriais, incluindo a função de pequenas fibras sensoriais (como por exemplo, o limiar térmico e o limiar de dor) e modalidade de fibras de grandes dimensões (como por exemplo, o limiar de vibração) ${ }^{23}$. Esses questionário identificam qualquer dor neuropática, independentemente da causa que esteja levando ao aparecimento dessa dor.

A aplicação desses testes tem mostrado que existem subgrupos distintos de pacientes que tem padrões específicos de sintomas e sinais sensoriais. A diferenciação desse fenótipo sensorial pode auxiliar na realização de ensaios clínicos randomizados como, por exemplo, de analgésicos podendo inserir o paciente de acordo com o fenótipo sensorial que pode ser mais sensível a um fármaco em particular ${ }^{23}$. 


\section{OBJETIVOS}

\subsection{Objetivo Geral}

Identificar dor com características neuropáticas em indivíduos com o diagnóstico de diabetes mellitus tipo 2 atendidos na atenção primária.

\subsection{Objetivos Específicos}

- $\quad$ Descrever o perfil sócio demográfico dos indivíduos;

- Identificar dor com características neuropáticas;

- $\quad$ Caracterizar a dor com características neuropáticas;

- $\quad$ Verificar a glicemia;

- Identificar as Estratégias de enfrentamento da dor com características neuropáticas. 


\section{METODOLOGIA}

\subsection{Delineamento do estudo}

Estudo transversal, prospectivo, quantitativo. Esses estudos destinam-se a estudar um processo ao longo do tempo para investigar mudanças, ou seja, refletem uma sequência de fatos $^{24}$.

\subsection{Local do estudo}

Esse estudo foi desenvolvido na Regional de Saúde de Ceilândia-DF. O projeto foi desenvolvido nos centros de saúde $n^{\circ} 02, n^{\circ} 03, n^{\circ} 05, n^{\circ} 06, n^{\circ} 07, n^{\circ} 08, n^{\circ} 09, n^{\circ} 11$ e $n^{\circ} 12$. Nesses Centros de Saúde são disponibilizadas as especialidades de Clínica Médica, Ginecologia/Obstetrícia, Pediatria e Odontologia e os programas especiais aos hipertensos, diabéticos, doenças sexualmente transmissíveis, tuberculose, hanseníase, cárie zero, automassagem, imunização e saúde da família.

\subsection{Duração do estudo}

O desenvolvimento desse estudo ocorreu durante o período de 18 meses.

\subsection{Amostra}

Foi executada uma amostragem aleatória simples sem reposição e composta por pacientes com diagnóstico de Diabetes Mellitus tipo 2 cadastrados no Programa de Diabetes de Centros de Saúde da Regional de Saúde de Ceilândia. A população de pacientes com Diabetes Mellitus tipo 2 em Ceilândia é composta por cerca de 9000 pacientes. Para o cálculo do tamanho de amostra foi considerado um plano amostral aleatório simples com população finita ${ }^{25}$. Neste contexto, para um erro máximo de 0,06 nas estimativas de proporções, com uma probabilidade $\alpha=6 \%$ do erro tipo I, o tamanho amostral deve ser no mínimo de 184 pacientes (Apêndice 1).

\subsection{Critérios de seleção da amostra}

Foram incluídos:

- Pacientes portadores de Diabetes Mellitus tipo 2; 
- Pacientes com idade igual ou superior a 18 anos até 60 anos;

- Pacientes com nível de consciência e cognição preservados.

Foram excluídos:

- Pacientes portadores de Diabetes Mellitus tipo 1;

- Pacientes com história de doença neurológica, endócrinas, infecciosas e neoplasias;

- Pacientes em uso rotineiro de bebida alcoólica;

- Pacientes com deficiências vitamínicas (B1, B6 e B12);

- Pacientes com feridas nos pés.

\subsection{Aspectos éticos}

Este projeto foi submetido ao Comitê de Ética em Pesquisa da Fundação de Ensino e Pesquisa em Ciências da Saúde (FEPECS) sob CAAE nº 30955914.3.0000.5553 (Anexo 1). Todos os sujeitos da pesquisa incluídos assinaram a aquiescência do Termo de Consentimento Livre e Esclarecido (TCLE) (Apêndice 2).

A liberdade do consentimento foi garantida para todos os sujeitos da pesquisa, assim como o sigilo e anonimato, assegurando a privacidade a estes quanto aos dados confidenciais envolvidos na pesquisa.

Todos os pacientes convidados, ou seus responsáveis legais, concordaram em participar de maneira voluntária, assinando o TCLE.

\subsection{Protocolo de coleta dos dados}

A pesquisa foi realizada em salas disponibilizadas pelos centros de saúde, os pacientes foram selecionados e agendados de acordo com a disponibilidade de cada centro de saúde.

O estudo foi realizado em 3 etapas:

Etapa I: Atendimento aos critérios da pesquisa e dados sócio demográficos.

Inicialmente foi realizada uma breve entrevista e análise de prontuários para verificação dos critérios de inclusão e de exclusão supracitados. Para os pacientes que atingiram os critérios de inclusão foi aplicado um questionário semiestruturado para a coleta de dados sócio demográficos.

Etapa II: Caracterização da dor com características neuropáticas, estratégias de enfrentamento da dor e verificação da glicemia. 
Para a caracterização da dor com características neuropáticas foi aplicado um questionário semiestruturado elaborado para atender aos objetivos da pesquisa com perguntas que questionavam a presença ou ausência de dor e os locais. $\mathrm{Na}$ ausência de dor, mais especificamente nos pés e/ou panturrilhas, o questionário era finalizado e na presença de dor nos pés e/ou panturrilhas, seguia-se com o questionário para a avaliação das características dessa dor e quais estratégias de enfrentamento eram utilizadas por esses pacientes para o alívio da dor.

O aspecto quantitativo da dor foi avaliado por meio da Escala Visual Analógica de Dor (EVA), nessa escala 0 (zero) indica ausência de dor e 10 dor insuportável. A aplicação da EVA foi subsidiada por uma régua numerada de 1 a $10 \mathrm{~mm}$. Dessa forma, os pacientes puderam visualizar e atribuir uma numeração para sua dor (em milímetros) que traduz a intensidade do sintoma: dor leve (menor que $4 \mathrm{~mm}$ ), dor moderada (entre 4 e 6,9 $\mathrm{mm}$ ), dor intensa ou insuportável (igual ou acima de $7 \mathrm{~mm}$ ). Trata-se de um método simples e de fácil avaliação da intensidade da dor, compatível com o nível de escolaridade da população abordada. Tal escala também é recomendada pela PORTARIA No 1.083 , DE 2 DE OUTUBRO DE $2012^{26}$.

A glicemia capilar foi verificada com o glicosímetro e realizada de acordo com as técnicas recomendadas pelo Ministério da $S_{a u ́ d e}{ }^{8}$. Os parâmetros utilizados para a glicemia considerada dentro dos valores toleráveis foram os seguintes: jejum ou pré-prandial até $130 \mathrm{mg} / \mathrm{dL}$ e pós-prandial até $180 \mathrm{mg} / \mathrm{dL}^{8}$.

Etapa III: Identificação da dor com características de neuropatia - Descrição e exame de função sensorial.

Participaram dessa etapa somente os pacientes com dor crônica, ou seja, com dor há mais de três meses e os pacientes com a glicemia dentro dos valores toleráveis ${ }^{27}$.

Para a identificação da dor com características neuropáticas foram realizados descrição sensorial e exames de função sensorial.

Para a descrição sensorial foi utilizada a Escala de Dor Leeds Assessment of Neuropathic Symptoms and Signs- LANSS (Anexo 2). Tal instrumento é considerado capaz de distinguir com boa confiabilidade uma dor de predomínio nociceptivo, neuropático ou misto, já existindo validação para o português do Brasil ${ }^{26,28,29}$. A escala vai de 0 a 24 pontos e consta de duas seções: uma que explora os aspectos qualitativos e outra os aspectos sensitivos da dor. Quando se utiliza tal escala leva-se em conta que para a avaliação da dor neuropática são fundamentais a presença de descritores verbais característicos (queimação, agulhadas, dormências), uma distribuição anatômica plausível e uma condição de base predisponente, como diabetes. $\mathrm{Na}$ escala de dor LANSS, os escores iguais ou superiores a 12 pontos indicam dor neuropática ${ }^{26,28}$, 
29. Tal escala ganha importância no Brasil por ser prevista na PORTARIA No 1.083 , DE 2 DE OUTUBRO DE 2012, que aprova o Protocolo Clínico e Diretrizes Terapêuticas da Dor Crônica ${ }^{26}$.

Para o exame de função sensorial foram utilizados os parâmetros aceitos para seu rastreamento pela Associação Americana de Diabetes (ADA -American Diabetes Association), Ministério da Saúde e protocolos adotados no âmbito da Coordenação Central de Diabetes do Governo do Distrito Federal: pesquisa da perda da sensibilidade protetora (PSP) com o monofilamento de $10 \mathrm{~g}$ e testes neurológicos: pino ou palito (sensibilidade dolorosa profunda), sensibilidade vibratória (diapasão $128 \mathrm{~Hz}$ ) e reflexo Aquileu $(\text { martelo })^{8,17}$. Se a perda da sensibilidade protetora for detectada associada a um e/ou mais dos testes neurológicos alterados, pode-se considerar que o paciente possui perda da função sensorial.

O teste do monofilamento de $10 \mathrm{~g}{ }^{30,31}$ foi realizado em 4 locais em ambos os pés, sendo feita sua aplicação duas vezes no mesmo local alternada com uma aplicação simulada, sendo um total de 09 aplicações, 3 em cada ponto (Figura 1). Em cada uma das aplicações o paciente foi questionado a respeito do local onde estava sendo aplicado o monofilamento. Considerouse como SENSAÇÃO PROTETORA PRESENTE se o paciente respondesse corretamente a duas das três aplicações, em cada ponto aplicado. A SENSAÇÃO PROTETORA foi considerada AUSENTE diante de duas respostas imprecisas das três aplicações, também válido para cada ponto. Se o paciente respondesse com imprecisão a um dos três pontos de aplicação também se considera SENSAÇÃO PROTETORA AUSENTE.

Figura 1 - Locais de Aplicação do Monofilamento de 10 g.

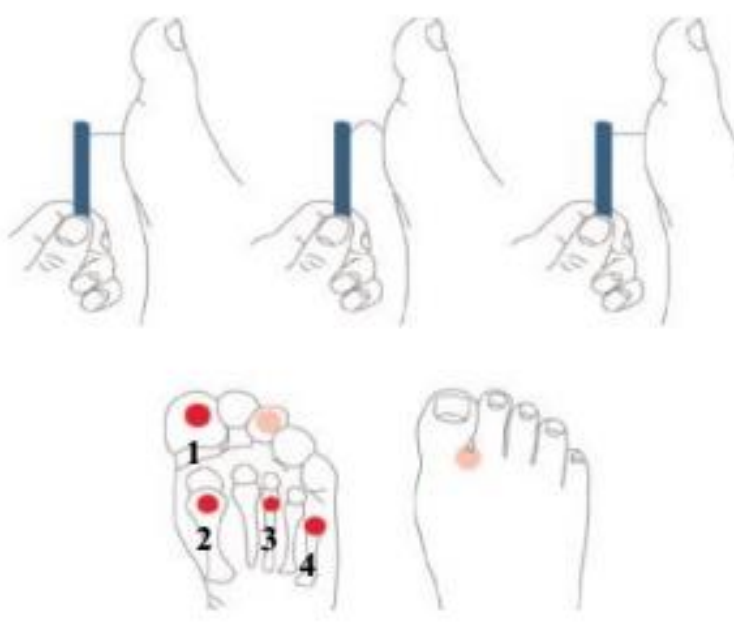

Fonte: Boulton AJ, Armstrong DG, Albert SF, Frykberg RG, Hellman R, Kirkman MS et al (2008). 
O teste para verificar a sensibilidade dolorosa foi realizado com um palito, o qual foi aplicado na superfície dorsal da pele próxima a unha do hálux. Sendo realizada três aplicações (uma delas simulada) no local e nos dois pés. Considerou-se como sensibilidade dolorosa AUSENTE se ele não referiu sensação em pelo menos duas das aplicações.

O teste de sensibilidade vibratória foi realizado utilizando um diapasão de $128 \mathrm{~Hz}$ no Apex do primeiro $1^{\circ}$ pododáctilo, sendo realizadas três aplicações (uma delas simulada). Considerou-se como sensibilidade vibratória AUSENTE se pelo menos dois pontos aplicados estivessem alterados.

O teste que avalia o Reflexo Aquileu foi realizado com um martelo neurológico. O paciente foi orientado a assumir a posição de joelhos em uma cadeira. A perna do paciente a ser submetida ao teste foi estabilizada com a mão do examinador e o martelo aplicado na altura do maléolo, diretamente sobre o tendão de Aquiles. Foram realizadas três tentativas e o reflexo foi considerado AUSENTE se o paciente não respondeu a nenhuma delas.

O teste de sensibilidade à temperatura foi realizado utilizando-se um diapasão que foi imergido no álcool por 10 segundos, para o seu resfriamento, realizada a sua aplicação no aspecto dorsal das cabeças dos 5 metatarsos. Foram realizadas 3 aplicações, sendo uma delas simuladas. Considerou-se sensibilidade à temperatura AUSENTE se duas das aplicações estivessem alteradas.

\subsection{Tratamento estatístico}

Os dados coletados foram submetidos à codificação apropriada e digitados em banco de dados, mediante a elaboração de um dicionário (code book) na planilha do EXCEL. Ainda, foram submetidos ao processo de validação por dupla digitação e, posteriormente, exportados para o Statistical Package for the Social Sciense (SPSS, versão 20.0).

Para responder aos objetivos do estudo utilizou-se, além de técnicas básicas de análise exploratória como média, mediana, desvio padrão, frequência absoluta e relativa, a análise estatística: os testes de Qui-Quadrado, de Mann-Withney, do Sinal e o Exato de Fisher.

O teste de Mann-Withney foi utilizado para avaliar a associação entre variáveis categóricas e quantitativas, enquanto o teste de Qui-Quadrado para independência e o teste exato de Fisher foram utilizados quando o objetivo foi avaliar a associação entre duas variáveis categóricas. O teste de Qui-Quadrado para a igualdade de proporções foi utilizado para avaliar a igualdade de proporções entre categorias de uma mesma variável, e o Teste do Sinal foi utilizado para avaliar se há diferença de prevalência entre variáveis do tipo de dor, duas a duas. 
Todos os testes de hipóteses desenvolvidos nesse trabalho consideraram uma significância de 5\%, ou seja, a hipótese nula foi rejeitada quando p-valor foi menor ou igual a 0,05 . 


\section{RESULTADOS}

\subsection{Caracterização sócio demográfica}

O estudo incluiu no total 237 pacientes com diagnóstico de diabetes mellitus tipo 2 e que atendiam aos critérios de inclusão e exclusão. A amostra foi composta em $70,5 \%$ por pessoas do sexo feminino; a idade média foi de $51 \pm 6$ anos; $54 \%$ se autodeclararam pardos, $29 \%$ brancos, $15 \%$ negros e $2 \%$ amarelo (Tabela 2 ).

Em relação a região onde nasceu, $49 \%$ eram naturais da região nordeste, $32 \%$ da região centro oeste, $14 \%$ da região sudeste. A maioria dos pacientes era casado (55\%); $63 \%$ possuíam o ensino fundamental, $30 \%$ possuíam o ensino médio e $6 \%$ possuíam o ensino superior (Tabela 2).

Quanto a ocupação $30 \%$ eram donas de casa, 29,5\% dos pacientes diabéticos estavam empregados, $17 \%$ trabalhavam de forma autônoma (ou seja, por conta própria), $11 \%$ estavam desempregados, $7 \%$ estavam aposentados, $3 \%$ recebiam auxílio doença, $2 \%$ eram pensionista e $0,4 \%$ reformado. Já a ocupação segundo o setor de atividade remunerada $41 \%$ eram trabalhadores dos serviços, vendedores do comércio em lojas e mercados, $18 \%$ trabalhadores da produção de bens e serviços industriais, $12 \%$ eram técnicos de nível médio, $12 \%$ de outros setores e $11 \%$ não informaram. A maioria (73\%) afirmou que o sustento da família vem do trabalho e $84 \%$ afirmaram não receber nenhum benefício do governo (Tabela 2).

A renda familiar total foi em média de $\mathrm{R} \$ 2225,74 \pm 1572,80$ reais por mês; o número de pessoas que vivem da renda foi em média $4 \pm 2$ pessoas. A renda per capita, que é a renda familiar total dividida pelo total de pessoas que vivem da renda, foi em média $\mathrm{R} \$ 675,67$ $\pm 492,70$ reais por mês. A média do número de salários mínimos foi de 2,8 $\pm 2,0$ salários mínimos mensais. A média de pessoas que trabalham na família foi 1 pessoa e a média do benefício do governo recebido foi de $\mathrm{R} \$ 122,54 \pm 415,42$ reais (Tabela 2 ). 
Tabela 2 - Perfil sócio demográfico dos pacientes com diagnóstico de diabetes mellitus tipo 2 atendidos na atenção primária em Ceilândia. Ceilândia, DF, 2016.

(Continua na próxima página)

\begin{tabular}{|c|c|c|}
\hline Variáveis & $\mathbf{N}^{\mathbf{0}}$ & $\%$ \\
\hline \multicolumn{3}{|l|}{ Cor/Etnia } \\
\hline Branco (a) & 69 & $29 \%$ \\
\hline Pardo (a) & 127 & $54 \%$ \\
\hline Negro (a) & 36 & $15 \%$ \\
\hline Amarelo (a) & 5 & $2 \%$ \\
\hline Total & 237 & $100,0 \%$ \\
\hline \multicolumn{3}{|l|}{ Gênero } \\
\hline Masculino & 70 & $29,5 \%$ \\
\hline Feminino & 167 & $70,5 \%$ \\
\hline Total & 237 & $100,0 \%$ \\
\hline \multicolumn{3}{|l|}{ Naturalidade } \\
\hline Região Norte & 9 & $4 \%$ \\
\hline Região Nordeste & 116 & $49 \%$ \\
\hline Região Centro-Oeste & 76 & $32 \%$ \\
\hline Região Sudeste & 34 & $14 \%$ \\
\hline Região Sul & 2 & $1 \%$ \\
\hline Total & 237 & $100,0 \%$ \\
\hline \multicolumn{3}{|l|}{ Estado Civil } \\
\hline Solteiro (a) & 59 & $25 \%$ \\
\hline Casado (a) & 129 & $55 \%$ \\
\hline Divorciado (a) & 34 & $14 \%$ \\
\hline Viúvo (a) & 15 & $6 \%$ \\
\hline Total & 237 & $100,0 \%$ \\
\hline \multicolumn{3}{|l|}{ Escolaridade } \\
\hline Analfabeto (a) & 3 & $1 \%$ \\
\hline $\begin{array}{l}\text { Ensino fundamental } \\
\text { incompleto/completo }\end{array}$ & 149 & $63 \%$ \\
\hline Ensino médio incompleto/completo & 71 & $30 \%$ \\
\hline Ensino superior & 14 & $6 \%$ \\
\hline Total & 237 & $100 \%$ \\
\hline
\end{tabular}


Tabela 2 - Perfil sócio demográfico dos pacientes com diagnóstico de diabetes mellitus tipo 2 atendidos na atenção primária em Ceilândia. Ceilândia, DF, 2016.

(Continuação)

\begin{tabular}{|c|c|c|}
\hline \multicolumn{3}{|l|}{ Ocupação } \\
\hline Do Lar & 71 & $30 \%$ \\
\hline Empregado (a) & 70 & $29,5 \%$ \\
\hline Autônomo & 41 & $17 \%$ \\
\hline Desempregado (a) & 25 & $11 \%$ \\
\hline Aposentado (a) & 16 & $7 \%$ \\
\hline Auxílio Doença & 8 & $3 \%$ \\
\hline Pensionista & 5 & $2 \%$ \\
\hline Reformado (a) & 1 & $0,4 \%$ \\
\hline Total & 237 & $100 \%$ \\
\hline \multicolumn{3}{|l|}{$\begin{array}{l}\text { Ocupação segundo o setor de } \\
\text { atividade remunerada }^{1}\end{array}$} \\
\hline $\begin{array}{l}\text { Membros superiores do poder } \\
\text { público, dirigentes de organizações } \\
\text { de interesse público e de empresas e } \\
\text { gerentes }\end{array}$ & 9 & $6 \%$ \\
\hline Técnicos de nível médio & 17 & $12 \%$ \\
\hline $\begin{array}{l}\text { Trabalhadores dos serviços, } \\
\text { vendedores do comércio em lojas e } \\
\text { mercados }\end{array}$ & 59 & $41 \%$ \\
\hline $\begin{array}{l}\text { Trabalhadores da produção de bens e } \\
\text { serviços industriais }\end{array}$ & 25 & $18 \%$ \\
\hline Outros Setores & 17 & $12 \%$ \\
\hline Não informou & 16 & $11 \%$ \\
\hline Total & 143 & $100 \%$ \\
\hline \multicolumn{3}{|l|}{$\begin{array}{l}\text { O sustento da família vem do } \\
\text { trabalho }\end{array}$} \\
\hline Sim & 174 & $73 \%$ \\
\hline Não & 63 & $27 \%$ \\
\hline Total & 237 & $100,0 \%$ \\
\hline \multicolumn{3}{|l|}{ Recebe Benefício do governo } \\
\hline Sim & 37 & $16 \%$ \\
\hline Não & 200 & $84 \%$ \\
\hline Total & 237 & $100 \%$ \\
\hline
\end{tabular}


Tabela 2 - Perfil sócio demográfico dos pacientes com diagnóstico de diabetes mellitus tipo 2 atendidos na atenção primária em Ceilândia. Ceilândia, DF, 2016.

\begin{tabular}{lccc}
\hline Variável & Média & DP $^{\mathbf{2}}$ & (Conclusão) \\
\hline Idade & 51 & 6 & 52 \\
Renda familiar total mensal & 2225,74 & 1572,80 & 1970,00 \\
$\begin{array}{l}\text { Número de pessoas que vivem da } \\
\text { renda }\end{array}$ & 4 & 2 & 4 \\
Renda per capita ${ }^{3}$ & 675,67 & 492,60 & 500,00 \\
Número de salários mínimos ${ }^{3}$ & 2,8 & 2,0 & 2,5 \\
Número de pessoas que trabalham & 1 & 1 & 1 \\
Valor do benefício em reais & 122,54 & 415,42 & 0,00 \\
\hline
\end{tabular}

Fonte: dados da pesquisa (2016).

Notas: ${ }^{1}$ Ocupação - Realizado de acordo com a Classificação de Ocupação Brasileira do Ministério do Trabelho e Emprego. DP 2 - Desvio Padrão. ${ }^{3} \mathrm{O}$ valor do salário mínimo considerado para os cálculos foi de $\mathrm{R} \$ 788,00$.

\subsection{Presença ou ausência de dor}

Em relação a presença ou ausência de dor 97,5\% dos pacientes sentiam dor. Foi detectada diferença estatisticamente significativa $(\mathrm{p}<0,000)$ (Figura 2).

A maioria $(71,9 \%)$ referiu dor em mais de um local (figura 3).

Figura 2 - Presença ou ausência de dor nos pacientes com diagnóstico de diabetes mellitus tipo 2 atendidos na atenção primária em Ceilândia. Ceilândia, DF, 2016.

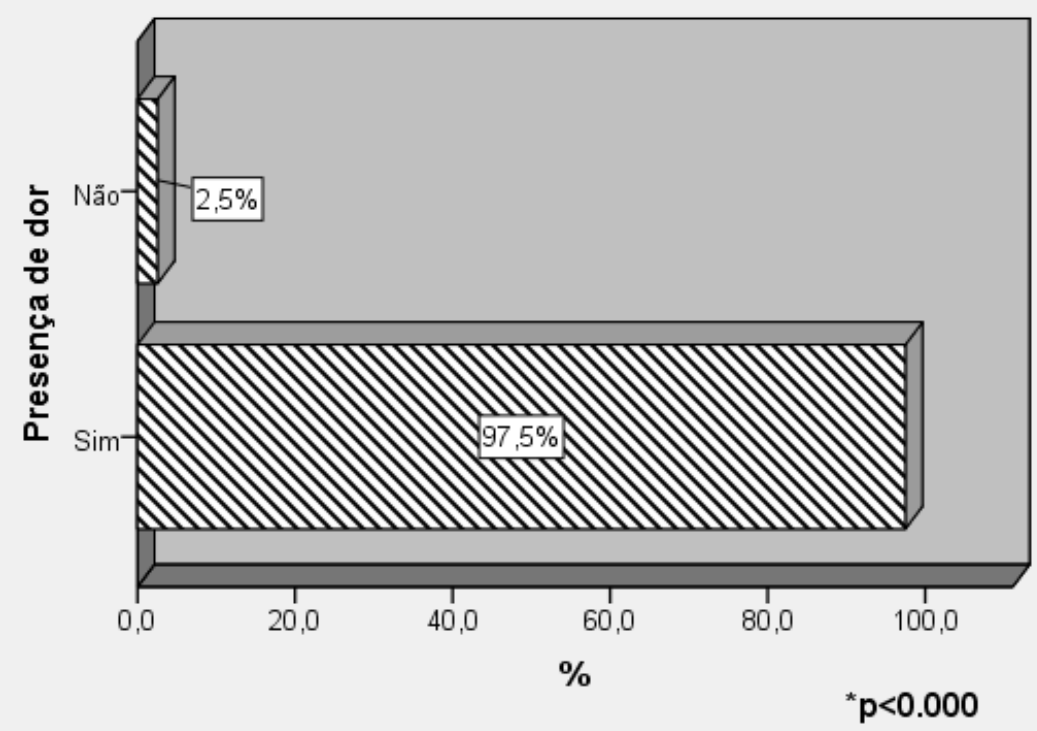

Fonte: Dados da pesquisa (2016).

Notas: *Teste Qui-quadrado 
Figura 3 - Locais de dor nos pacientes com diagnóstico de diabetes mellitus tipo 2 atendidos na atenção primária em Ceilândia. Ceilândia, DF, 2016.

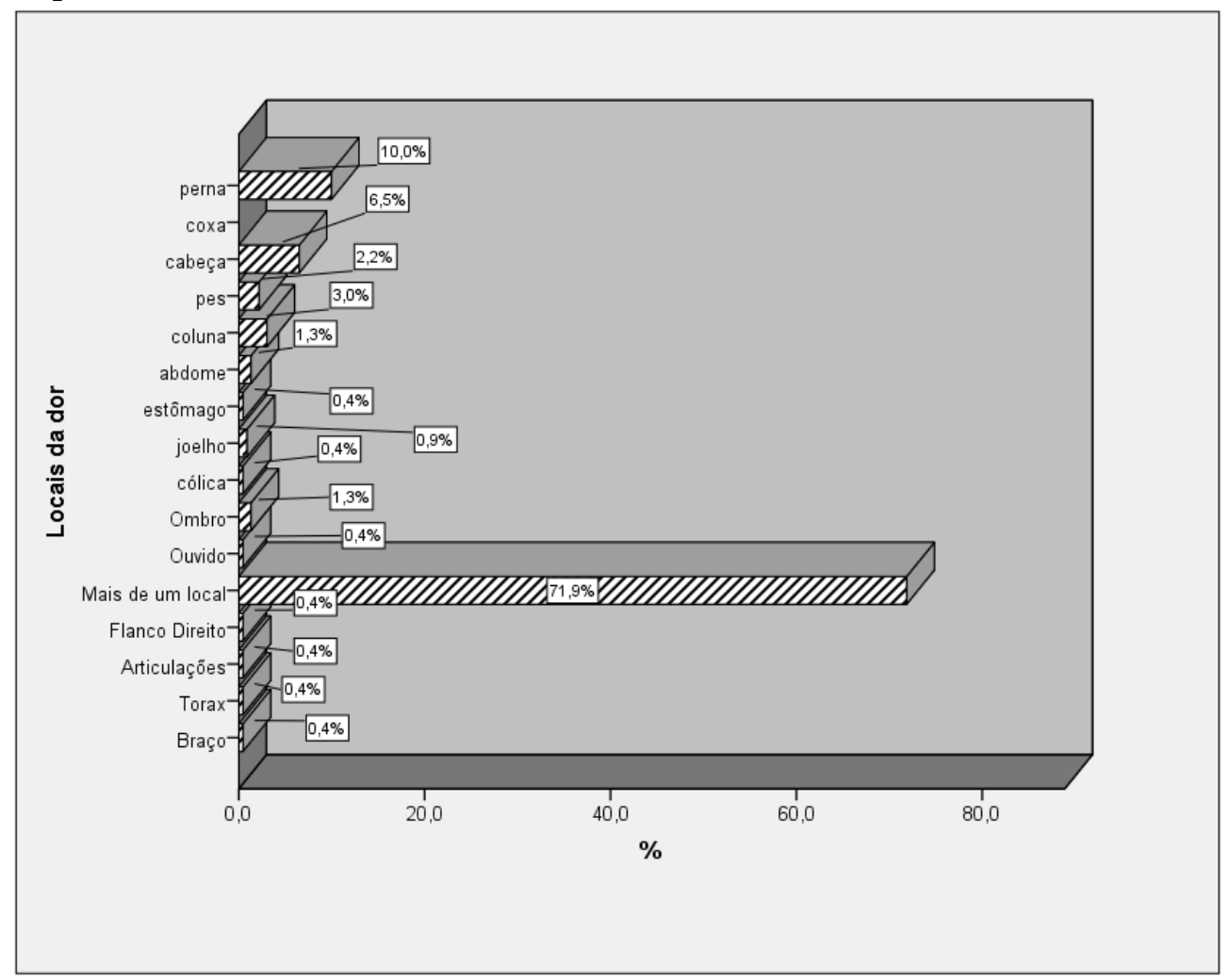

Fonte: Dados da pesquisa (2016).

Avaliando-se a presença de dor em pernas e/ou panturrilhas, independentemente de ser a sua dor principal ou não, observa-se que $94 \%$ da amostra tem este tipo de dor, sendo este percentual estatisticamente maior (p-valor $<0.000$ ) do que o percentual de quem não sente este tipo de dor 6\% (Figura 4). 
Figura 4 - Dor nos pés e/ou panturrilhas nos pacientes com diagnóstico de diabetes mellitus tipo 2 atendidos na atenção primária em Ceilândia. Ceilândia, DF, 2016.

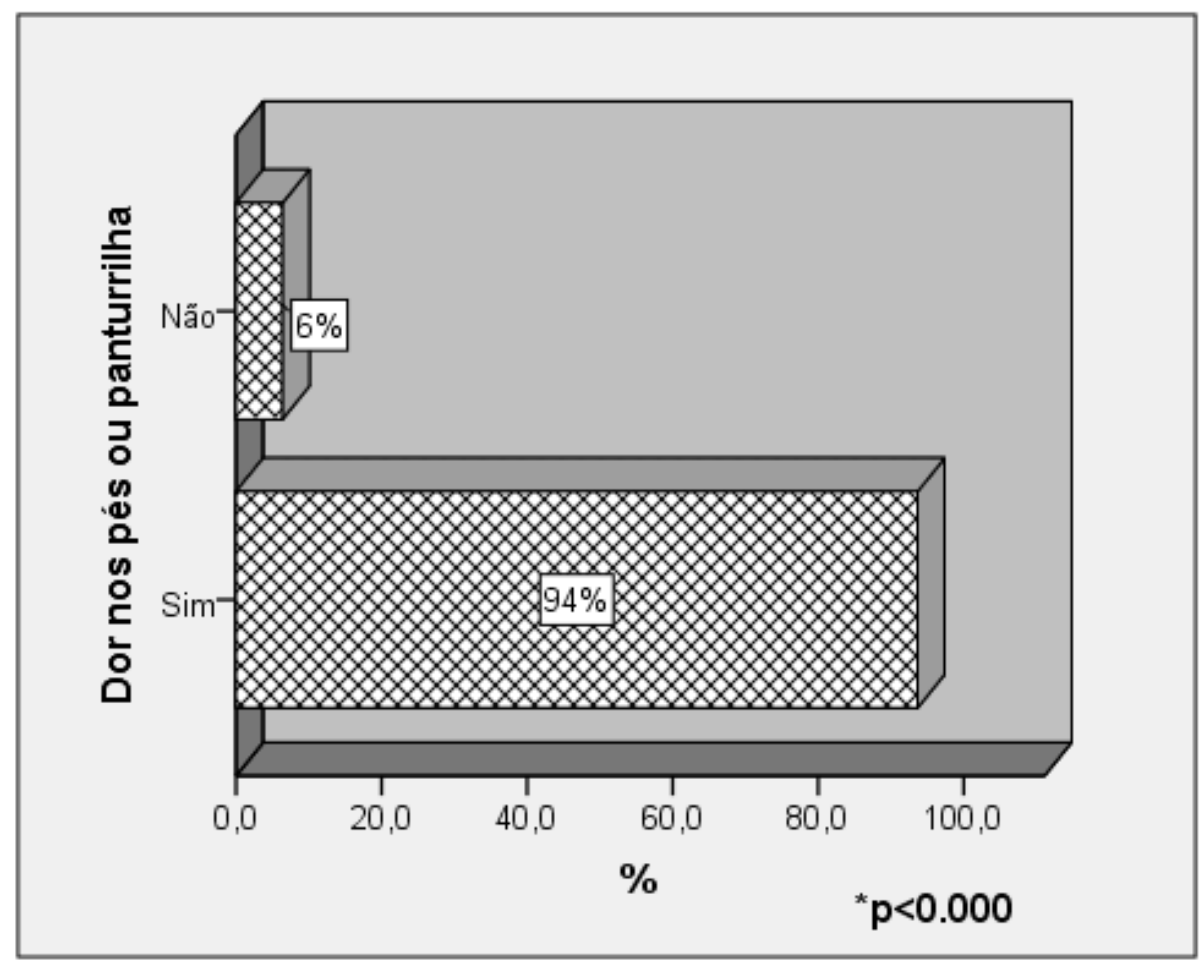

Fonte: Dados da pesquisa (2016).

Notas: *Teste Qui-quadrado

\subsection{Estratégias de enfrentamento da dor com características neuropática}

Dos pacientes com dor nos pés e/ou panturrilhas (Figura 4 ) a maioria $(59,7 \%)$ relatou não informar sobre a dor nas consultas na Unidade Básica de Saúde (UBS). Dos pacientes que informaram sobre a dor nas consultas, $83,1 \%$ informou ao médico (Tabela 3).

As condutas mais adotadas pelos profissionais relatadas pelos pacientes foram: prescrição de medicamentos para a dor $(30,3 \%)$ e orientação quanto ao controle glicêmico $(28,1 \%)$ (Tabela 3$)$.

A média (em porcentagem) para o grau de alívio com o uso das condutas adotadas pelos profissionais foi de $44 \% \pm 37 \%$ de alívio (Tabela 3 ). 
Tabela 3 - Estratégias para o enfrentamento da dor dos pacientes com diagnóstico de diabetes mellitus tipo 2 atendidos na atenção primária em Ceilândia. Ceilândia, DF, 2016.

(Continua na próxima página)

\begin{tabular}{lcc}
\hline Variável & N & $\%$ \\
\hline Informou sobre a dor nas consultas na UBS & & \\
Sim & 89 & $40,3 \%$ \\
Não & 132 & $59,7 \%$ \\
Total & 221 & $100,0 \%$ \\
Se sim, qual o profissional que atendeu & & \\
Médico & 74 & $83,1 \%$ \\
Enfermeiro & 3 & $3,4 \%$ \\
Médico e enfermeiro & 11 & $12,4 \%$ \\
Outro & 1 & $1,1 \%$ \\
Total & 89 & $100,0 \%$
\end{tabular}

Relato das condutas adotadas pelo profissional

Prescrição de medicamentos para dor

Orientação quanto ao controle glicêmico

$25 \quad 28,1 \%$

Prescrição de Anti-hipertensivos

Não soube informar

Nenhuma

14

$15,7 \%$

Vitamina D

4

$4,5 \%$

Cirurgia perivascular

1

$1,1 \%$

Ácido acetilsalicílico

1

$1,1 \%$

Raio-X

1

$1,1 \%$

Prescrição de medicamentos para dor e orientações

6

$6,7 \%$ quanto ao controle glicêmico

Fitoterápicos

Total

89

$100,0 \%$

Grau de alivio (\%) 
Tabela 3 - Estratégias para o enfrentamento da dor dos pacientes com diagnóstico de diabetes mellitus tipo 2 atendidos na atenção primária em Ceilândia. Ceilândia, DF, 2016.

(Conclusão)

\begin{tabular}{lc}
\hline DP1 & 37 \\
Mediana & 50 \\
Mínimo & 0 \\
Máximo & 100
\end{tabular}

Fonte: Dados da pesquisa (2016).

Notas: DP ${ }^{1}$ - Desvio Padrão.

Em relação ao relato de uso de estratégias não orientadas por profissionais para o enfrentamento da dor, a maioria $(74,2 \%)$ dos pacientes com dor nos pés e/ou panturrilhas referiu seu uso (Tabela 4).

Quanto a automedicação a maioria (75\%) relatou não fazer o uso de automedicação para o alívio da dor. No que diz respeito ao posicionamento 46,7\% referiram mudar de posição para o alivio da dor, 29,3\% movimentam-se e 22,7\% repousam para aliviar a dor (Tabela 4).

Das outras estratégias utilizadas para o alívio da dor a mais relatadas foram: massagem (37\%) e massagem com gel de arnica $(32,1 \%)$ (Tabela 4).

A média (em porcentagem) para o grau de alívio com o uso dessas estratégias não orientadas por profissionais foi de $67 \% \pm 29 \%$ de alívio (Tabela 4). 
Tabela 4 - Outras estratégias para o enfrentamento da dor dos pacientes com diagnóstico de diabetes mellitus tipo 2 atendidos na atenção primária em Ceilândia. Ceilândia, DF, 2016.

(Continua na próxima página)

\begin{tabular}{l}
\hline Variável \\
\hline Uso de estratégias não orientadas por \\
profissionais \\
Sim \\
Não \\
Total \\
Relato das estratégias para o manejo da dor - \\
Automedicação
\end{tabular}

Sim

41

$25,0 \%$

Não

$75,0 \%$

Total

$164 \quad 100,0 \%$

Relato das estratégias para o manejo da dor Posicionamento

Movimenta-se

$29,3 \%$

Repousa

17

$22,7 \%$

Caminha

1

$1,3 \%$

Mudança de posição

35

$46,7 \%$

Total

75

$100,0 \%$

Relato de outras Estratégias para o manejo da dor

Massagem

30

$37,0 \%$

Massagem com gel de arnica

26

$32,1 \%$

Passar álcool

3

$3,7 \%$

Alongamento

1

$1,2 \%$

Estica a Perna

2

$2,5 \%$

Compressa com água morna

5

$6,2 \%$

Atividade Física

5

$6,2 \%$

Compressa com bolsa de gelo

2

$2,5 \%$ 
Tabela 4 - Outras estratégias para o enfrentamento da dor dos pacientes com diagnóstico de diabetes mellitus tipo 2 atendidos na atenção primária em Ceilândia. Ceilândia, DF, 2016.

\begin{tabular}{lcc} 
& & (Conclusão) \\
\hline Fitoterápicos & 3 & $3,7 \%$ \\
Passar Creme & 4 & $4,9 \%$ \\
Total & 81 & $100,0 \%$
\end{tabular}

\begin{tabular}{lc}
\hline Grau de alivio (\%) & \\
\hline Média & 67 \\
DP1 & 29 \\
Mediana & 80 \\
Mínimo & 0 \\
Máximo & 100
\end{tabular}

Fonte: Dados da pesquisa (2016).

Notas: DP1 - Desvio Padrão.

\subsection{Caracterização da dor com características neuropáticas}

As características da dor nos pés e/ou panturrilhas mais relatadas por 93,6\% dos pacientes (Figura 3) foram: fadiga $(22,4 \%)$, seguida de câimbras $(17,1 \%)$, queimação $(14,6 \%)$, formigamento $(14,1 \%)$, dormência $(14 \%)$ e alfinetada e/ou agulhada $(10,4 \%)$. A maioria dos pacientes $(62 \%)$ sentia a dor há mais de 6 meses. No que diz respeito a frequência da dor $47,5 \%$ sentiam a dor as vezes, $27,6 \%$ sentiam frequentemente e $24,9 \%$ sentiam continuamente (o tempo todo). A maioria (53\%) afirmou que a dor nunca incomodou a ponto de acordar (Tabela $5)$.

Dos pacientes que sentiam dor nos pés e/ou panturrilhas continuamente $32,7 \%$ afirmaram que a dor piorava durante o dia e a noite, $25,5 \%$ durante o dia, 23,6\% durante a noite e 18,2\% afirmaram que a dor não piorava, era sempre igual (Tabela 5).

Dos pacientes que não sentiam dor contínua nos pés e/ou panturrilhas, 34,9\% afirmaram que a dor piorava durante o dia e a noite, $34,9 \%$ afirmou que a dor piorava durante a noite e $30,2 \%$ que a dor piorava durante o dia. A maioria (63,3\%) também afirmou que quando a dor aparecia ela permanecia por algumas horas e depois passava (Tabela 5).

A média da menor dor já sentida foi de $4 \pm 3$ pontos, a média da maior dor já sentida foi de $8 \pm 4$ pontos e a média da dor média já sentida foi de $5 \pm 2$ pontos (Tabela 5 ). 
Tabela 5 - Caracterização da dor nos pés e/ou panturrilhas dos pacientes com diagnóstico de diabetes mellitus tipo 2 atendidos na atenção primária em Ceilândia. Ceilândia, DF, 2016.

(Continua na próxima página)

\begin{tabular}{|c|c|c|}
\hline Variáveis & $\mathbf{N}$ & $\%$ \\
\hline \multicolumn{3}{|l|}{$\begin{array}{l}\text { Frequência das Características da dor } \\
\text { nos pés e/ou panturrilhas }\end{array}$} \\
\hline Queimação & 97 & $14,6 \%$ \\
\hline Dormência & 93 & $14,0 \%$ \\
\hline Formigamento & 94 & $14,1 \%$ \\
\hline Fadiga & 149 & $22,4 \%$ \\
\hline Câimbras & 114 & $17,1 \%$ \\
\hline Prurido & 44 & $6,6 \%$ \\
\hline Alfinetada e/ou agulhada & 69 & $10,4 \%$ \\
\hline Outra & 5 & $0,8 \%$ \\
\hline Total & 665 & $100 \%$ \\
\hline \multicolumn{3}{|l|}{ Tempo que sente a dor } \\
\hline Há menos de três meses & 20 & $9 \%$ \\
\hline Há mais de três meses e menos que seis & 31 & $14 \%$ \\
\hline Mais de 6 meses & 136 & $62 \%$ \\
\hline Há mais de um ano & 34 & $15 \%$ \\
\hline Total & 221 & $100 \%$ \\
\hline \multicolumn{3}{|l|}{ Frequência da dor } \\
\hline Às vezes & 105 & $47,5 \%$ \\
\hline Frequentemente (mas nem sempre) & 61 & $27,6 \%$ \\
\hline Continuamente (o tempo todo) & 55 & $24,9 \%$ \\
\hline Total & 221 & $100 \%$ \\
\hline \multicolumn{3}{|l|}{$\begin{array}{l}\text { Caso a dor seja continua ela costuma } \\
\text { piorar }\end{array}$} \\
\hline Dia & 14 & $25,5 \%$ \\
\hline Noite & 13 & $23,6 \%$ \\
\hline Dia e noite & 18 & $32,7 \%$ \\
\hline Não piora, é sempre igual & 10 & $18,2 \%$ \\
\hline Total & 55 & $100,0 \%$ \\
\hline \multicolumn{3}{|l|}{$\begin{array}{l}\text { Caso a dor não seja contínua ela } \\
\text { costuma piorar }\end{array}$} \\
\hline Dia & 50 & $30,2 \%$ \\
\hline Noite & 58 & $34,9 \%$ \\
\hline Dia e noite & 58 & $34,9 \%$ \\
\hline Total & 166 & $100,0 \%$ \\
\hline
\end{tabular}

Quando a dor não contínua aparece ela permanece

$\begin{array}{lcc}\text { Algumas horas } & 105 & 63,3 \% \\ \text { Metade do dia } & 19 & 11,4 \% \\ \text { O dia todo } & 29 & 17,5 \% \\ \text { Uma parte da semana } & 5 & 3,0 \% \\ \text { A semana toda } & 6 & 3,6 \% \\ \text { Uma parte do mês } & 1 & 0,6 \% \\ \text { O mês todo } & 1 & 0,6 \% \\ \text { Total } & 166 & 100 \%\end{array}$


Tabela 5 - Caracterização da dor nos pés e/ou panturrilhas dos pacientes com diagnóstico de diabetes mellitus tipo 2 atendidos na atenção primária em Ceilândia. Ceilândia, DF, 2016.

(Conclusão)

\begin{tabular}{lcc}
\hline A dor já incomodou a ponto de acordar & & \\
Nunca incomodou a ponto de acordar & 117 & $53 \%$ \\
Às vezes & 58 & $26,2 \%$ \\
Frequentemente (mas nem sempre) & 27 & $12,2 \%$ \\
Continuamente (o tempo todo) & 19 & $8,6 \%$ \\
Total & 221 & $100 \%$ \\
Caso a dor não seja contínua ela & & \\
costuma piorar & & \\
Dia & 50 & $30,2 \%$ \\
Noite & 58 & $34,9 \%$ \\
Dia e noite & 58 & $34,9 \%$ \\
Total & 166 & $100,0 \%$ \\
Quando a dor não contínua aparece ela & & \\
permanece & & \\
Algumas horas & 105 & $63,3 \%$ \\
Metade do dia & 19 & $11,4 \%$ \\
O dia todo & 29 & $17,5 \%$ \\
Uma parte da semana & 5 & $3,0 \%$ \\
A semana toda & 6 & $3,6 \%$ \\
Uma parte do mês & 1 & $0,6 \%$ \\
O mês todo & 1 & $0,6 \%$ \\
Total & 166 & $100 \%$ \\
A dor já incomodou a ponto de acordar & & \\
Nunca incomodou a ponto de acordar & 117 & $52,9 \%$ \\
Âs vezes & 58 & $26,2 \%$ \\
Frequentemente (mas nem sempre) & 27 & $12,2 \%$ \\
Continuamente (o tempo todo) & 19 & $8,6 \%$ \\
Total & 221 & $100 \%$ \\
Escala Visual Analógica & $\mathbf{D P}$ \\
\hline Pontuação da MENOR dor já sentida & 3 \\
Pontuação da MAIOR dor já sentida & 5 & 3 \\
Pontuação da dor MÉDIA & & 4 \\
\hline Fo: Da & 2 \\
\hline
\end{tabular}

Fonte: Dados da pesquisa (2016).

Notas: DP1 - Desvio Padrão.

Quando comparado as características da dor nos pés e/ou panturrilhas relatadas pelos pacientes foi detectada diferença estatisticamente significativa entre a prevalência de fadiga e câimbra, ou seja, a fadiga apresenta, estatisticamente, a maior prevalência dentre todos os tipos de dor. Em seguida, câimbra mostrou-se estatisticamente diferente de dormência; e alfinetada mostrou-se estatisticamente diferente de queimação, formigamento, dormência e outras (Tabela $6)$. 
Tabela 6 - Comparação entre as características da dor nos pés e/ou panturrilhas relatadas pelos pacientes com diagnóstico de diabetes mellitus tipo 2 atendidos na atenção primária em Ceilândia. Ceilândia, DF, 2016.

\begin{tabular}{llr}
\hline & Comparação & P-valor* \\
\hline Fadiga & Câimbras & $\mathbf{0 . 0 0 0}$ \\
\hline Câimbras & Queimação & 0.106 \\
& Formigamento & 0.051 \\
& Dormência & $\mathbf{0 . 0 3 7}$ \\
\hline Queimação & Formigamento & 0.755 \\
& Dormência & 0.688 \\
& Alfinetada & $\mathbf{0 . 0 0 1}$ \\
\hline Formigamento & Dormência & 0.913 \\
& Alfinetada & $\mathbf{0 . 0 0 1}$ \\
\hline Dormência & Alfinetada & $\mathbf{0 . 0 0 7}$ \\
\hline Alfinetada & Outra & $<\mathbf{0 . 0 0 0}$ \\
\hline
\end{tabular}

Fonte: dados da pesquisa (2016).

Notas: *Teste do Sinal

\subsection{Glicemia e tempo do diagnóstico de diabetes mellitus}

A média da glicemia em jejum dos pacientes foi de $148 \pm 61 \mathrm{mg} / \mathrm{dL}$, a média da glicemia pós-prandial foi de $199 \pm 100 \mathrm{mg} / \mathrm{dL}$ e $75,1 \%$ das glicemias foram realizadas após as refeições (Tabela 7).

Para a glicemia capilar 52,5\% dos pacientes se encontravam com a glicemia dentro dos valores toleráveis. Não foi detectada diferença estatisticamente significativa entre as proporções de "sim" e "não" (p < 0.459) (Figura 5). 
Tabela 7 - Valor da glicemia e tipo de glicemia dos pacientes com diagnóstico de diabetes mellitus tipo 2 atendidos na atenção primária em Ceilândia. Ceilândia, DF, 2016.

\begin{tabular}{|c|c|c|c|}
\hline \multicolumn{4}{|c|}{ Tipo de glicemia } \\
\hline \multicolumn{2}{|c|}{ Jejum (<130mg/dL) } & \multicolumn{2}{|c|}{ Pós-prandial (<180mg/dL) } \\
\hline $\mathbf{N}$ & $\%$ & $\mathbf{N}$ & $\%$ \\
\hline 55 & $24,90 \%$ & 166 & $75,10 \%$ \\
\hline \multicolumn{4}{|c|}{ Valor da glicemia em jejum } \\
\hline Média & $\mathbf{D P}^{1}$ & Mediana & Mínimo \\
\hline 148 & 61 & 137 & 48 \\
\hline \multicolumn{4}{|c|}{ Valor da glicemia pós-prandial } \\
\hline Média & $\mathbf{D P}^{1}$ & Mediana & Mínimo \\
\hline 199 & 100 & 170 & 52 \\
\hline
\end{tabular}

Fonte: Dados da pesquisa (2016).

Notas: DP ${ }^{1}$ - Desvio Padrão.

Figura 5 - Valores de glicemia capilar apresentados por pacientes com diagnóstico de diabetes mellitus tipo 2 atendidos na atenção primária que tem dor nos pés e/ou panturrilhas. Ceilândia, DF, 2016.

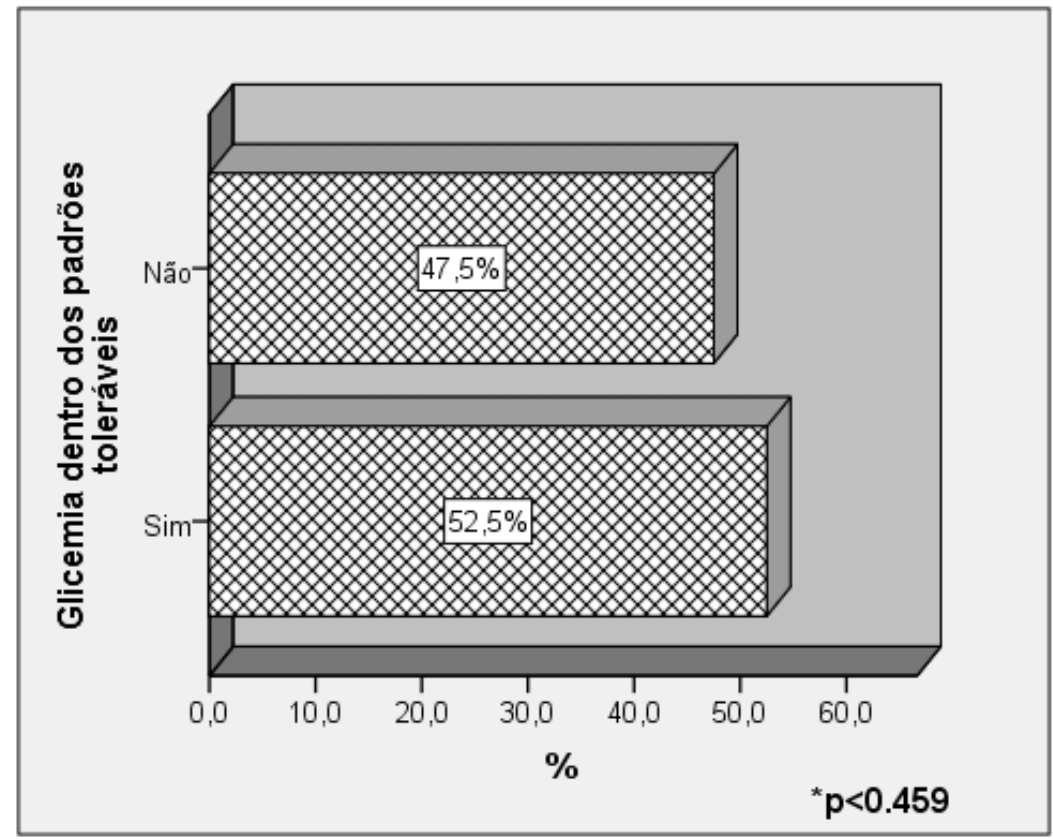

Fonte: Dados da pesquisa (2016).

Notas: *Teste Qui-quadrado.

No que se refere ao tempo de diagnóstico de diabetes mellitus, 79,69\% dos pacientes com dor nos pés e/ou panturrilhas tem o diagnóstico há < de 10 anos e 20,31\% tem o diagnóstico 
há $\geq 10$ anos. Foi detectada diferença estatisticamente significativa para tempo de diabetes $(\mathrm{p}<0.000)$ (Tabela 8).

Tabela 8 - Frequência absoluta e relativa do tempo de diabetes dos pacientes com diagnóstico de diabetes mellitus tipo 2 atendidos na atenção primária em Ceilândia. Ceilândia, DF, 2016.

\begin{tabular}{ccc}
\hline \multirow{2}{*}{ Categorias } & \multicolumn{2}{c}{ Tempo de diabetes } \\
\cline { 2 - 3 } & $\mathrm{N}$ & $\%$ \\
\hline$<10$ anos & 204 & 79,69 \\
$\geq 10$ anos & 52 & 20,31 \\
\hline$*$ p-valor & & $<\mathbf{0 . 0 0 0}$ \\
\hline
\end{tabular}

Fonte: Dados da pesquisa (2016).

Notas: *Teste do Qui-quadrado

4.6. Identificação da dor com características neuropáticas - descrição e exame da função sensorial.

Dos 221 pacientes com dor nos pés e/ou panturrilhas (Figura 3), 116 estão com a glicemia dentro dos valores toleráveis (Figura 5) e desses 104 (91\%) sentem dor há mais de 3 meses (Tabela 9).

Não foi detectada associação estatisticamente significativa entre o tempo de diabetes e a glicemia dentro e a que não estava dentro dos valores toleráveis $(\mathrm{p}<0,480)$.

Em relação ao tempo de dor e o valor total das glicemias foi detectada diferença estatisticamente significativa $(\mathrm{p}<0,000)$ (Tabela 9). 
Tabela 9 - Frequência cruzada entre o tempo de dor e a glicemia dentro ou não dos padrões de normalidade; e entre o tempo de dor e o total das glicemias dos pacientes com diagnóstico de diabetes tipo 2 atendidos na atenção primária em Ceilândia. Ceilândia, DF, 2016.

\begin{tabular}{|c|c|c|c|c|c|}
\hline \multirow[t]{2}{*}{ Tempo de dor } & \multirow[t]{2}{*}{ Estatística } & \multicolumn{2}{|c|}{$\begin{array}{l}\text { Glicemia dentro dos padrões de } \\
\text { normalidade }\end{array}$} & \multicolumn{2}{|c|}{ Total } \\
\hline & & $1-\operatorname{Sim}$ & 2 - Não & $\mathrm{N}$ & $\%$ \\
\hline \multirow{2}{*}{$\begin{array}{c}\text { Menos } 3 \\
\text { meses }\end{array}$} & $\mathrm{N}$ & 12 & 8 & \multirow{2}{*}{20} & \multirow{2}{*}{9} \\
\hline & $\%$ linha & 60 & 40 & & \\
\hline \multirow{2}{*}{$\begin{array}{l}\text { Mais de } 3 \\
\text { meses }\end{array}$} & $\mathrm{N}$ & 104 & 97 & \multirow{2}{*}{\multicolumn{2}{|c|}{20191}} \\
\hline & $\%$ linha & 51,74 & 48,26 & & \\
\hline Total & & 116 & 105 & 221 & 100 \\
\hline p-valor & & & & $<0.0$ & $00 *$ \\
\hline
\end{tabular}

Fonte: dados da pesquisa (2016).

Nota: **teste Qui-quadrado para independência.

* teste Qui-quadrado para a igualdade de proporções.

Apenas os pacientes com a glicemia dentro dos valores toleráveis e que sentem dor há mais de 3 meses foram avaliados seguindo-se a escala de dor de LANNS e os testes para avaliação da função sensorial, sendo avaliados no total 104 pacientes. Na escala de dor de LANNS 87,5\% dos pacientes obtiveram o escore total $<12$ (Tabela 10).

A maioria $(87,5 \%)$ dos pacientes apresentaram o teste do monofilamento de $10 \mathrm{~g}$ normal em ambos os pés, $84 \%$ apresentaram o teste de sensibilidade vibratória normal em ambos os pés, 90,4\% apresentaram o teste de sensibilidade dolorosa profunda normal em ambos os pés, 93,3\% apresentaram o teste do reflexo Aquileu normal em ambos os pés e 94,2\% apresentaram o teste de sensibilidade a temperatura normal em ambos os pés (Tabela 10).

No que concerne a perda da sensibilidade protetora plantar a avaliação da maioria (78\%) dos pacientes revelou ausência de PSP em ambos os pés (Tabela 10). 
Tabela 10 - Descrição e Exame da função sensorial dos pacientes com diagnóstico de diabetes tipo 2 atendidos na Atenção Básica em Ceilândia com dor crônica e glicemia dentro dos valores toleráveis. Ceilândia, DF, 2016.

\begin{tabular}{|c|c|c|}
\hline Variáveis & $\mathbf{N}$ & $\%$ \\
\hline \multicolumn{3}{|l|}{ Descrição Sensorial } \\
\hline \multicolumn{3}{|l|}{ Escore da Escala de dor LANNS } \\
\hline Escore total $\geq 12$ & 13 & $12,5 \%$ \\
\hline Escore total $<12$ & 91 & $87,5 \%$ \\
\hline Total & 104 & $100 \%$ \\
\hline \multicolumn{3}{|l|}{ Exame de Disfunção Sensorial } \\
\hline \multicolumn{3}{|l|}{$\begin{array}{l}\text { Sensação de pressão (monofilamento } \\
\text { de } 10 \mathrm{~g} \text { ) }\end{array}$} \\
\hline Teste normal ambos os pés & 91 & $87,5 \%$ \\
\hline Teste anormal ambos os pés & 7 & $6,7 \%$ \\
\hline Teste anormal em pé. & 6 & $5,8 \%$ \\
\hline Total & 104 & $100,0 \%$ \\
\hline \multicolumn{3}{|c|}{ Sensibilidade vibratória (diapasão de } \\
\hline \multicolumn{3}{|l|}{$128 \mathrm{HZ})$} \\
\hline Teste normal ambos os pés & 87 & $84 \%$ \\
\hline Teste anormal ambos os pés & 9 & $9 \%$ \\
\hline Teste anormal em um pé. & 8 & $7 \%$ \\
\hline Total & 104 & $100 \%$ \\
\hline \multicolumn{3}{|l|}{$\begin{array}{l}\text { Sensibilidade dolorosa profunda } \\
\text { (palito) }\end{array}$} \\
\hline Teste normal ambos os pés & 94 & $90,4 \%$ \\
\hline Teste anormal ambos os pés & 10 & $9,6 \%$ \\
\hline Teste anormal em um pé. & 0 & $0,0 \%$ \\
\hline Total & 104 & $100,0 \%$ \\
\hline \multicolumn{3}{|l|}{ Reflexo Aquileu (martelo) } \\
\hline Teste normal ambos os pés & 97 & $93,3 \%$ \\
\hline Teste anormal ambos os pés & 7 & $6,7 \%$ \\
\hline Total & 104 & $100,0 \%$ \\
\hline \multicolumn{3}{|l|}{ Sensibilidade à temperatura } \\
\hline Teste normal ambos os pés & 98 & $94,2 \%$ \\
\hline Teste anormal ambos os pés & 3 & $2,9 \%$ \\
\hline Teste anormal em um pé. & 3 & $2,9 \%$ \\
\hline Total & 104 & $100,0 \%$ \\
\hline \multicolumn{3}{|l|}{$\begin{array}{l}\text { Perda da sensibilidade protetora } \\
\text { plantar }\end{array}$} \\
\hline PSP em um pé & 8 & $7,6 \%$ \\
\hline PSP em ambos os pés & 15 & $14,4 \%$ \\
\hline Descartada PSP em ambos os pés & 81 & $78 \%$ \\
\hline Total & 104 & $100 \%$ \\
\hline
\end{tabular}

Fonte: Dados da pesquisa (2016).

Notas: DP ${ }^{1}$ - Desvio Padrão. 
A média do escore de dor de LANNS é igual a 16,54, com mediana igual a 16 e desvio padrão de 3,33 para os indivíduos com escore LANNS total maior ou igual a 12. Já para os indivíduos com escore LANNS total menor que 12 temos média igual a 3,8, mediana de 3 e desvio padrão de 3,82. Houve diferença estatística da média, mediana e desvio padrão entre o escore total $\geq$ e escore total $<12(\mathrm{p}<0.000)$ (Tabela 11).

Tabela 11 - Média, mediana e desvio padrão dos valores da escala LANNS por classificação LANNS. Ceilândia, DF, 2016.

\begin{tabular}{lccc}
\hline \multirow{2}{*}{$\begin{array}{c}\text { Classificação } \\
\text { LANNS }\end{array}$} & \multicolumn{3}{c}{ Valor dos escores da Escala de dor de } \\
LANNS
\end{tabular}

No que diz respeito aos questionários e testes da Escala de dor LANNS, quando o escore total é $\geq 12$, a maioria $(92,3 \%)$ pontuou a primeira pergunta, $76,9 \%$ pontuou a segunda pergunta, $61,5 \%$ pontuou a terceira pergunta e quarta pergunta respectivamente, $84,6 \%$ pontou a quinta pergunta, 53,8\% tiveram sensação normal em ambas as áreas no teste de sensibilidade para alodinia e 61,5\% tiveram alteração do limiar por estímulo de agulha (Tabela 12).

Quando o escore é < 12 a maioria $(68,1 \%)$ não pontuou a primeira pergunta, 87,9\% não pontuou a segunda pergunta, $94,5 \%$ não pontou a terceira pergunta, $70,3 \%$ não pontuou a quarta pergunta, 59,3\% não pontou a quinta pergunta. Em relação ao exame de sensibilidade para alodinia a maioria $(97,8 \%)$ tiveram sensação normal em ambas as áreas e 90,1\% teve o limiar por estímulo de agulha não alterado (Tabela 12). 
Tabela 12 - Escore total da Escala de dor LANNS segundo a Escala de dor LANNS nos pacientes com diagnóstico de diabetes mellitus tipo 2 com dor nos pés e/ou panturrilhas atendidos na Atenção Básica em Ceilândia. Ceilândia, DF, 2016.

(Continua na próxima página)

Escore Total da Escala de dor

Escala de dor LANNS

LANNS

Questionário de Dor da Escala de dor LANNS

Pergunta 1 - A sua dor se parece com uma sensação estranha e desagradável na pele? Palavras como "agulhadas", "choques elétricos" e "formigamento" são as que melhor descrevem estas sensações.

Não pontuou a pergunta

Pontuou a Pergunta

Total

Pergunta 2 - A sua dor faz com que a cor da pele dolorida mude de cor? Palavras como "manchada" ou "avermelhada ou rosada" descrevem a aparência da sua pele.

Não pontuou a pergunta

Pontuou a Pergunta

Total

Pergunta 3 - A sua dor faz com a pele afetada fique sensível ao toque? Sensações desagradáveis ou dolorosas ao toque leve ou mesmo ao toque da roupa ao vestir-se descrevem esta sensibilidade anormal.

Não pontuou a pergunta

Pontuou a Pergunta

Total

Pergunta 4 - A sua dor inicia de repente ou em crises, sem nenhuma razão aparente, quando você está parado, sem fazer nenhum movimento? Palavras como "choques elétricos", "dor em pontada" ou "dor explosiva" descrevem estas sensações.

Não pontuou a pergunta

Pontuou a Pergunta

Total

Pergunta 5 - A sua dor faz com que a temperatura da sua pele na área dolorida mude? Palavras como "calor" e "queimação" descrevem estas sensações.

Não pontuou a pergunta

\begin{tabular}{cccc} 
Escore total $\geq 12$ & \multicolumn{2}{c}{ Escore total $<12$} \\
\hline $\mathbf{N}$ & $\%$ & $\mathbf{N}$ & $\%$
\end{tabular}

$1 \quad 7,7 \% \quad 62 \quad 68,1 \%$

$\begin{array}{llll}12 & 92,3 \% & 29 & 31,9 \%\end{array}$

$13 \quad 100 \% \quad 91 \quad 100 \%$

$3 \quad 23,1 \% \quad 80 \quad 87,9 \%$

$10 \quad 76,9 \% \quad 11 \quad 12,1 \%$

$13 \quad 100 \% \quad 91 \quad 100 \%$

$5 \quad 38,5 \% \quad 86 \quad 94,5 \%$

$8 \quad 61,5 \% \quad 5 \quad 5,5 \%$

$13 \quad 100 \% \quad 91 \quad 100 \%$

$\begin{array}{llll}5 & 38,5 \% & 64 & 70,3 \% \\ 8 & 61,5 \% & 27 & 29,7 \% \\ 13 & 100 \% & 91 & 100 \%\end{array}$

$2 \quad 15,4 \% \quad 54 \quad 59,3 \%$ 
Tabela 12 - Escore total da Escala de dor LANNS segundo a Escala de dor LANNS nos pacientes com diagnóstico de diabetes mellitus tipo 2 com dor nos pés e/ou panturrilhas atendidos na Atenção Básica em Ceilândia. Ceilândia, DF, 2016.

(Conclusão)

\begin{tabular}{lcccc}
\hline Pontuou a Pergunta & 11 & $84,6 \%$ & 37 & $40,7 \%$ \\
$\quad$ Total & 13 & $100 \%$ & 91 & $100 \%$ \\
$\begin{array}{l}\text { Exames da Sensibilidade - Alodinia } \\
\text { Sensação normal em ambas as áreas }\end{array}$ & 7 & $53,8 \%$ & 89 & $97,8 \%$ \\
$\quad$ Alodinia somente nas áreas doloridas & 6 & $46,2 \%$ & 2 & $2,2 \%$ \\
$\quad$ Total & 13 & $100 \%$ & 91 & $100 \%$ \\
$\begin{array}{l}\text { Exames da Sensibilidade - Alteração do limiar } \\
\text { por estímulo de agulha } \\
\text { Limiar por estímulo de agulha não alterado }\end{array}$ & 5 & $38,5 \%$ & 82 & $90,1 \%$ \\
$\quad \begin{array}{l}\text { Alteração do limiar por estímulo de agulha } \\
\quad\end{array}$ & 8 & $61,5 \%$ & 9 & $9,9 \%$ \\
$\quad$ Total & 13 & $100 \%$ & 91 & $100 \%$ \\
\hline
\end{tabular}

Fonte: dados da pesquisa (2016).

Em relação ao escore total $\geq 12$ pontos da escala de dor LANNS $69,2 \%$ dos pacientes tiveram o teste do monofilamento de $10 \mathrm{~g}$ normal em ambos os pés. No teste de sensibilidade dolorosa profunda a maioria $(84,6 \%)$ teve o teste normal em ambos os pés. A maioria $(84,6 \%)$ teve o teste de vibração normal em ambos os pés. Todos os pacientes (100\%) tiveram reflexo de Aquileu normal em ambos os pés. No teste de sensibilidade a temperatura 84,6\% teve esse teste normal. Na PSP 69,2\% foi descartado PSP (Tabela 13).

Os pacientes com escore < 12 pontos da escala de dor LANNS, a maioria $(90,1 \%)$ teve o teste do monofilamento de $10 \mathrm{~g}$ normal em ambos os pés. A maioria $(91,2 \%)$ teve o teste de sensibilidade dolorosa profunda normal em ambos os pés, $83,5 \%$ teve o teste de sensibilidade vibratória normal em ambos os pés, 92,3\% teve o reflexo de Aquileu normal em ambos os pés e 95,6\% teve o teste de sensibilidade a temperatura normal em ambos os pés. Em relação a PSP $79,1 \%$ tiveram descartada PSP (Tabela 13 ).

Foi avaliada, estatisticamente, a associação dos resultados dos testes com o Escore LANNS. Na Tabela 16 temos que 90\% dos indivíduos que apresentaram Escore LANNS menor que 12 apresentaram teste normal ambos os pés em monofilamento, enquanto dentre os indivíduos que apresentaram Escore LANNS maior ou igual a 12 essa proporção foi de $69 \%$. Observou-se diferença estatística entre o monofilamento e o escore de dor LANNS $(\mathrm{p}<0.022)$

Não foi detectada associação estatisticamente significativa de nenhum dos outros testes com o Escore LANNS ( $>0.05)$ (Tabela 13). 
Tabela 13 - Frequência cruzada entre resultados dos testes e Escore de dor LANNS. Ceilândia, DF, 2016.

\begin{tabular}{|c|c|c|c|c|c|c|}
\hline \multirow[b]{2}{*}{ Variável } & \multirow[b]{2}{*}{ Categoria } & \multirow[b]{2}{*}{ Estatística } & \multicolumn{2}{|c|}{ ESCORE LANNS } & \multirow[b]{2}{*}{ Total } & \multirow[b]{2}{*}{$\begin{array}{l}* \mathrm{p}- \\
\text { valor }\end{array}$} \\
\hline & & & $\begin{array}{c}\text { Escore total } \\
<=12\end{array}$ & $\begin{array}{l}\text { Escore } \\
\text { total }>12\end{array}$ & & \\
\hline \multirow[t]{6}{*}{ Monofilamento } & \multirow{2}{*}{$\begin{array}{l}\text { Teste anormal ambos } \\
\text { os pés }\end{array}$} & $\mathrm{N}$ & 6 & 1 & 7 & $\mathbf{0 , 0 2 2 3}$ \\
\hline & & $\%$ coluna & 7 & 8 & . & \\
\hline & \multirow{2}{*}{$\begin{array}{l}\text { Teste anormal em um } \\
\text { pé }\end{array}$} & $\mathrm{N}$ & 3 & 3 & 6 & \\
\hline & & $\%$ coluna & 3 & 23 & . & \\
\hline & \multirow{2}{*}{$\begin{array}{l}\text { Teste normal ambos } \\
\text { os pés }\end{array}$} & $\mathrm{N}$ & 82 & 9 & 91 & \\
\hline & & $\%$ coluna & 90 & 69 & . & \\
\hline \multirow{6}{*}{$\begin{array}{l}\text { Sensibilidade } \\
\text { Vibratória }\end{array}$} & \multirow{2}{*}{$\begin{array}{l}\text { Teste anormal ambos } \\
\text { os pés }\end{array}$} & $\mathrm{N}$ & 7 & 2 & 9 & 0,4109 \\
\hline & & $\%$ coluna & 8 & 15 & . & \\
\hline & \multirow{2}{*}{$\begin{array}{l}\text { Teste anormal em um } \\
\text { pé }\end{array}$} & $\mathrm{N}$ & 8 & 0 & 8 & \\
\hline & & $\%$ coluna & 9 & 0 & . & \\
\hline & \multirow{2}{*}{$\begin{array}{l}\text { Teste normal ambos } \\
\text { os pés }\end{array}$} & $\mathrm{N}$ & 76 & 11 & 87 & \\
\hline & & $\%$ coluna & 84 & 85 & . & \\
\hline \multirow{6}{*}{$\begin{array}{l}\text { Sensibilidade } \\
\text { Dolorosa }\end{array}$} & \multirow{2}{*}{$\begin{array}{l}\text { Teste anormal ambos } \\
\text { os pés }\end{array}$} & $\mathrm{N}$ & 83 & 11 & 94 & 0,6096 \\
\hline & & $\%$ coluna & 91 & 85 & . & \\
\hline & \multirow{2}{*}{$\begin{array}{l}\text { Teste anormal em um } \\
\text { pé }\end{array}$} & $\mathrm{N}$ & 0 & 0 & 0 & \\
\hline & & $\%$ coluna & 0 & 0 & . & \\
\hline & \multirow{2}{*}{$\begin{array}{l}\text { Teste normal ambos } \\
\text { os pés }\end{array}$} & $\mathrm{N}$ & 8 & 2 & 10 & \\
\hline & & $\%$ coluna & 9 & 15 & . & \\
\hline Reflexo & \multirow{2}{*}{$\begin{array}{l}\text { Teste anormal ambos } \\
\text { os pés }\end{array}$} & $\mathrm{N}$ & 84 & 13 & 97 & 0,5921 \\
\hline \multirow[t]{5}{*}{ Aquileu } & & $\%$ coluna & 92 & 100 & . & \\
\hline & \multirow{2}{*}{$\begin{array}{l}\text { Teste anormal em um } \\
\text { pé }\end{array}$} & $\mathrm{N}$ & 0 & 0 & 0 & \\
\hline & & $\%$ coluna & 0 & 0 & . & \\
\hline & \multirow{2}{*}{$\begin{array}{l}\text { Teste normal ambos } \\
\text { os pés }\end{array}$} & $\mathrm{N}$ & 7 & 0 & 7 & \\
\hline & & $\%$ coluna & 8 & 0 & . & \\
\hline Sensibilidade & Teste anormal ambos & $\mathrm{N}$ & 2 & 1 & 3 & 0,1623 \\
\hline \multirow[t]{5}{*}{ Temperatura } & os pés & $\%$ coluna & 2 & 8 & . & \\
\hline & \multirow{2}{*}{$\begin{array}{l}\text { Teste anormal em um } \\
\text { pé }\end{array}$} & $\mathrm{N}$ & 2 & 1 & 3 & \\
\hline & & $\%$ coluna & 2 & 8 & . & \\
\hline & \multirow{2}{*}{$\begin{array}{l}\text { Teste normal ambos } \\
\text { os pés }\end{array}$} & $\mathrm{N}$ & 87 & 11 & 98 & \\
\hline & & $\%$ coluna & 96 & 85 & . & \\
\hline \multirow[t]{6}{*}{ PSP } & \multirow[t]{2}{*}{ Descartada PSP } & $\mathrm{N}$ & 72 & 9 & 81 & 0,5613 \\
\hline & & $\%$ coluna & 91 & 90 & . & \\
\hline & PSP em ambos os pés & $\mathrm{N}$ & 0 & 0 & 0 & \\
\hline & & $\%$ coluna & 0 & 0 & 0 & \\
\hline & PSP em um pé & $\mathrm{N}$ & 7 & 1 & 8 & \\
\hline & & $\%$ coluna & 9 & 10 & . & \\
\hline
\end{tabular}

Fonte: dados da pesquisa (2016).

Notas: * teste exato de Fisher. 
Não foi detectada associação estatisticamente significativa entre o escore da escala de dor LANNS, PSP relacionados ao tempo de diabetes ( $p>0,05)$. Dessa forma podemos afirmar, estatisticamente, que o Escore de dor LANNS e PSP independem do tempo de diabetes (Tabela 14).

Tabela 14 - Frequência cruzada entre tempo de diabetes e escore LANNS e PSP. Ceilândia, DF, 2016.

\begin{tabular}{|c|c|c|c|c|c|c|}
\hline \multirow[b]{2}{*}{ Variável } & \multirow[b]{2}{*}{ Categoria } & \multirow[b]{2}{*}{ Estatística } & \multicolumn{2}{|c|}{ Tempo de diabetes } & \multirow[b]{2}{*}{ Total } & \multirow[b]{2}{*}{$\mathrm{p}$-valor } \\
\hline & & & $<10$ anos & $\geq 10$ anos & & \\
\hline \multirow{4}{*}{$\begin{array}{l}\text { Escore da } \\
\text { escala de dor } \\
\text { LANNS }\end{array}$} & Escore total $<12$ & $\mathrm{~N}$ & 73 & 18 & 91 & 1,0000 \\
\hline & & $\%$ linha & 80 & 20 & . & \\
\hline & Escore total $\geq 12$ & $\mathrm{~N}$ & 11 & 2 & 13 & \\
\hline & & $\%$ linha & 85 & 15 & - & \\
\hline \multirow[t]{4}{*}{ PSP } & PSP em ambos & $\mathrm{N}$ & 70 & 11 & 81 & 0,1082 \\
\hline & & $\%$ linha & 86 & 14 & . & \\
\hline & PSP em um pé & $\mathrm{N}$ & 5 & 3 & 8 & \\
\hline & & $\%$ linha & 63 & 38 & . & \\
\hline
\end{tabular}

Fonte: dados da pesquisa (2016).

Notas: * teste exato de Fisher. 


\section{DISCUSSÃO}

O presente estudo buscou descrever o perfil sócio demográfico, identificar e caracterizar a dor com características neuropáticas em indivíduos com o diagnóstico de diabetes mellitus tipo 2 atendidos na atenção primária.

A média da idade da amostra do estudo foi de $51 \pm 6$ anos e a maioria eram pessoas também eram do sexo feminino, esses dados são parecidos com os encontrados em estudos realizados no Brasil e no mundo que mostram que a prevalência do diabetes aumenta com a idade, sendo as maiores prevalências a partir de 50 anos de idade. $\mathrm{O}$ aumento da prevalência de DM nessa faixa etária, também está relacionada a longevidade dos pacientes e o aparecimento de comorbidades, como o DM. Nesses estudos a maioria da população também era formada por pessoas do sexo feminino ${ }^{31,32,33,34}$. Não existe uma relação direta entre sexo feminino e maior prevalência de DM, o que observa-se é uma maior procura dos serviços de saúde das mulheres e a maioria da população de Ceilândia também é formada por mulheres, o que justifica elas serem também a maioria da amostra do estudo.

A pesquisa distrital por amostra de domicílios (PDAD) do ano de 2015, mostra que a população de Ceilândia é formada, em sua maioria, por pessoas do sexo feminino, 40,34\% tem acima de 40 anos de idade, a maioria dos residentes se declararam pardo, houve a prevalência de solteiros, seguidos pelos casados. No levantamento dos residentes, $48,33 \%$ da população não nasceu no DF, sendo a maioria desses naturais da região nordeste. Quanto ao nível de escolaridade, a população concentra-se na categoria dos que têm nível fundamental incompleto, $35,96 \%$, seguido pelo médio completo, 23,94\%. Em relação a ocupação 44,94\% da população tem alguma atividade remunerada, 17,51\% são estudantes, 13,27\% são aposentados, 10,27\% são donas de casa e $8,26 \%$ desempregados. No que diz respeito a ocupação remunerada o setor que mais se destaca na cidade é o comércio, seguido por serviços gerais, 42,65\% da população tem renda domiciliar de 2 a 5 salários mínimos, seguido por $21,62 \%$ que tem renda familiar de 1 a 2 salários mínimos ${ }^{35}$.

Nosso estudo revela que os pacientes com o diagnóstico de diabetes mellitus tipo 2 difere muito pouco da realidade da população geral de Ceilândia, as diferenças observadas são: a maioria das pessoas serem casadas, seguido pelas solteiras; a escolaridade, a maioria se concentra na categoria do ensino fundamental incompleto, seguido pelo fundamental completo; a situação de ocupação também é diferente, pois a população não tem estudantes e o percentual de donas de casa é maior que o de aposentados. 
Estudos mostram que a posição socioeconômica mais baixa está associada com o DM e que as desigualdades socioeconômicas estão relacionadas com a mortalidade e morbidade da doença e tem sido motivo de preocupação em muitos países ${ }^{36,37,38}$. Um estudo realizado na Suécia (país desenvolvido) mostrou que níveis baixos de escolaridade (estudar em média 9 anos) estão associados ao aumento do percentual de pessoas com diabetes mellitus tipo $2^{39}$. Alguns comportamentos como por exemplo consumo de alimentos e atividades físicas estão ligados as desigualdades sociais, sendo, portanto, o acesso universal aos cuidados de saúde um fator importante ${ }^{40}$. Esse acesso universal aos cuidados de saúde se dá desde a promoção de políticas públicas voltadas ao saneamento básico, educação, emprego, moradia ao desenvolvimento de políticas de saúde voltada para os trabalhadores, idosos, donas de casa entre outros grupos.

A maioria dos pacientes da nossa pesquisa estudou até nove anos aproximadamente (o que corresponde ao ensino fundamental completo), temos um percentual considerável de pessoas com atividade remunerada (sendo o principal setor o comércio seguido do setor de serviços gerais) e também de donas de casa, a renda familiar é formada por em média 2,8 salários mínimos.

Nesse caso as políticas de saúde e as intervenções relacionadas ao tratamento do DM devem ser específicas para cada grupo, já que, por exemplo, os trabalhadores não têm tempo em horário comercial de irem as consultas, palestras, realizarem atividade física e muitas vezes por falta de programas saudáveis voltados para esse público, eles não tem uma alimentação adequada (como relatado por muitos pacientes durante a pesquisa); as donas de casas e desempregados não possuem muitas vezes renda suficiente para arcar com o tratamento, que inclui alimentação adequada e o hábito da prática de atividade física. O fato da maioria da população ter baixos níveis de escolaridade também é um fator importante a ser considerado no planejamento de estratégias ligadas a promoção, prevenção e tratamento dessa população.

Tratamento inadequado e a falta de adesão ao tratamento levam a hiperglicemia, sendo ela o principal fator de desencadeamento de complicações. A neuropatia diabética - ND é uma das principais complicações do DM, ocasionada principalmente pela hiperglicemia, caracterizada pela presença de sintomas e/ou sinais de disfunção dos nervos periféricos sensoriais, motores e autonômicos - em pessoas com o diagnóstico de diabetes mellitus após exclusão de outras causas ${ }^{1,5}$.

A ND pode ser dolorosa e não dolorosa. As características dessa dor (chamada de dor neuropática diabética) é dor nos pés e/ou panturrilhas com os seguintes descritores de dor: dor lancinante (comparada a facada), ardente, choque elétrico, queimação, alfinetada e agulhada, 
dormência, formigamento desconfortável e dor de contato provocada pelo toque de meias durante o dia e meias ou roupas de cama durante à noite (alodinia). Estão presentes também sensações subjetivas de percepção de temperatura alterados como sensações de pés ou pernas muito frios ou muito quentes. A dor neuropática diabética tende a ser de moderada a intensa, principalmente à noite, resultando muitas vezes em distúrbios do sono que somado ao sintoma doloroso também durante o dia pode levar o paciente a diminuição das atividades de vida diária $^{5,41}$. O que pode-se observar no estudo é que a maioria dos pacientes referem dor nos pés e/ou panturrilhas (mesmo não sendo a dor que mais incomoda). As características dessa dor nos pés e/ou panturrilhas mais relatadas pelos pacientes foram: fadiga, câimbras, queimação, formigamento, dormência, alfinetada e/ou agulhada. A intensidade da dor foi de moderada a intensa, mais da metade sente dor ou durante a noite ou dia e noite e, para um percentual considerável de pessoas (47\%), a dor já incomodou a ponto de acordar.

Um estudo realizado em centros multidisciplinares de dor na França comparando os sinais e sintomas entre grupos com dor neuropática e sem dor neuropática, mostrou que as características mais relatadas pelos pacientes com dor neuropática e com significância estatística quando comparadas ao grupo sem dor neuropática foram: queimação, alfinetada e agulhada, dormência, choque elétrico, formigamento, coceira ${ }^{42}$. Outros 2 estudos realizados no Brasil um no ambulatório de neuropatias periféricas e dor neuropática do Hospital Universitário Antonio Pedro e outro em uma clínica de tratamento multidisciplinar da dor mostrou queimação e formigamento como os descritores mais frequentes para dor neuropática ${ }^{43}, 44$. Com exceção de choque elétrico e coceira, todas as outras características apresentadas pelos participantes desse estudo francês foram encontradas nos pacientes da pesquisa. Pode-se observar também que nos estudos e no nosso, queimação aparece entre as três características mais frequentes.

Os sintomas isolados não são específicos para o diagnóstico de ND, mas auxiliam na sua identificação, sendo o primeiro passo para uma avaliação mais específica ${ }^{41}$. Neste caso, são importantes parâmetros a serem investigados na consulta de enfermagem ao diabético em atenção primária. Comparando-se os dados do estudo com o que mostra a literatura, pode-se concluir que a dor nos pés e/ou panturrilhas dos pacientes tem características neuropáticas.

O controle glicêmico faz parte tanto do tratamento da ND como do diabetes, reduzindo a incidência de ambos e a falta desse controle é um dos principais fatores que levam ao aparecimento da ND tanto dolorosa quanto não dolorosa ${ }^{5}$.

Uma parte da amostra tinha controle glicêmico e outra parte não realizava o controle glicêmico. Isso é preocupante, principalmente quando se pensa na prevenção das complicações do DM. O fato desses pacientes realizarem o acompanhamento na atenção primária facilita a 
investigação da falta do controle glicêmico e a implementação de estratégias de educação em saúde para atingir essa parcela da população.

Dentro dos programas da atenção primária, existe a estratégia de saúde da família (ESF), onde uma equipe multidisciplinar atendem os pacientes em suas próprias residências, facilitando o acesso a saúde. Segundo dados da Secretaria de Saúde do Distrito Federal (SESDF), a cobertura da ESF hoje no DF é de apenas 30,7\%, além da atenção primária possuir baixa resolutividade ${ }^{45}$. Por outro lado tem-se também os profissionais, que não são suficientes para atender a demanda e que fazem tudo ao seu alcance para atender esses pacientes com qualidade. Isso reflete diretamente na quantidade de pacientes encontrados na pesquisa que estão com a glicemia capilar acima dos padrões toleráveis, que encontram dificuldades para marcação de consultas e na adesão do tratamento (como relatado por eles durante a pesquisa).

Nos casos das ND dolorosas um grande número de agentes terapêuticos tem sido utilizado no tratamento dos sintomas dolorosos e são eles: antidepressivos tricíclicos, inibidores seletivos da receptação de serotonina, anticonvulsivantes e antiarrítmicos. Alguns tratamentos tópicos como a capsaicina e nitrato tópico também tem demonstrado efeitos eficazes no tratamento da dor. Terapias físicas como acupuntura, estimulação percutânea do nervo e estimulação da medula espinhal elétrica tem sido utilizados também para o controle da dor ${ }^{1,5,41}$.

Em relação ao tratamento observa-se que a maioria dos pacientes não relatou a dor que sentem nos pés e/ou panturrilhas na atenção básica e, para os que relataram, a condutas orientadas não foram eficazes. Nesse caso, a maioria desses pacientes recorreu a estratégias não orientadas por profissionais de saúde para enfretamento da dor, sendo que essas estratégias foram mais eficazes. Porém, nenhuma das estratégias, tanto orientadas por profissionais de saúde, quanto utilizadas sem orientação, foram realmente eficazes no controle da dor. Pode-se sugerir tal ineficácia por meio da análise do relato de continuarem a sentir a dor e com uma intensidade moderada a intensa.

Outro ponto a ser considerado é o tratamento recomendado pela literatura que são medicações consideradas de alto custo tanto para os pacientes, quanto para o sistema de saúde, sendo, portanto, inviável a aplicação desses tratamentos na realidade da atenção primária. Nesse caso específico a aplicação de uma terapêutica com menor custo e que fosse eficaz para a dor desses pacientes seria mais adequada.

Estudos têm demonstrado que com o passar dos anos com o diagnóstico de DM, se não houver controle glicêmico rigoroso, a tendência é que ocorra lesão do sistema nervoso periférico e com isso se tenha a neuropatia diabética ${ }^{5,34,46}$. A maioria da amostra do estudo ainda não tem perda da sensibilidade protetora plantar, ou seja, ainda não tem ND. Apesar de não ter 
encontrado dependência entre PSP, escala de dor LANNS e o tempo de diabetes, o que justifica uma grande parcela ainda não ter ND é o tempo de DM ser menor de 10 anos para a maioria. Para confirmar os dados acerca do tempo de DM demonstrado pelos estudos e pela literatura, seria necessário o acompanhamento dessa amostra daqui há alguns anos e ver se o percentual de pessoas com ND aumentou ou não.

A dor ainda pode ser provocada por vários mecanismos e ela reflete de um modo geral o que está ocorrendo no organismo. A dor pode ser um sistema fisiológico de proteção essencial para detectar e minimizar o contato com estímulos prejudiciais ou nocivos. Essa dor chamada de nociceptiva, é a dor que sentimos quando tocamos algo muito quente, frio ou afiado. A dor pode ser, também, um mecanismo adaptativo e protetor, chamada de dor inflamatória, é causada pela ativação do sistema imunitário por lesão ou infecção de tecido. Existe ainda a dor patológica que não é o sintoma de alguma doença, mas sim um estado de doença do sistema nervoso, pode ocorrer após o dano do sistema nervoso (dor neuropática), mas também em condições que não existe tal dano (dor disfuncional) ${ }^{47}$.

A maioria $(79,1 \%)$ dos pacientes não tem dor com possíveis mecanismos neuropáticos de acordo com a escala de dor LANNS, nem alteração nos testes, porém apresentam sintomas característicos de dor neuropática. O processo inflamatório sistêmico provocado pela hiperglicemia, resistência à insulina, perda da sinalização da insulina e/ou dislipidemia pode ser o que está contribuindo para a dor desses pacientes que não foram identificados com dor neuropática pela escala de dor LANNS. Pelo fato da dor nociceptiva e inflamatória serem respostas protetoras do organismo, a hipótese levantada aqui é de que esses pacientes vêm sofrendo processos inflamatórios sucessivos, porém ainda não há dano suficiente para o paciente apresentar fenótipo de dor neuropática que possa ser detectado por instrumentos como a Escala de dor LANNS. Como visto, a incidência da ND aumenta com o tempo de diagnóstico de DM e mais da metade dos pacientes da pesquisa tem menos de 10 anos com o diagnóstico, o que também pode explicar que os danos no sistema nervoso periférico ainda podem ocorrer ao longo dos anos e ocasionar fenótipo acentuado suficientemente para detectar-se a dor neuropática por tal instrumento.

A presença de neuropatia indica que há lesões no sistema somatossensorial desses pacientes, que é o processo que leva ao aparecimento da dor neuropática. Os exames para a avaliação da função sensorial, avaliam fibras mielinizadas (fibras A- $\beta$ ), fibras pouco mielinizadas $(\mathrm{A}-\delta)$ e fibras não mielinizadas $(\mathrm{C})$, a dor neuropática pode aparecer quando há lesão nas fibras de pequeno e grande diâmetro, com o avanço da lesão no sistema somatossensorial a tendência é que as grandes fibras sejam atingidas, o que pode fazer com que 
a dor neuropática continue ou desapareça. Portanto, podem aparecer ambos os tipos de perdas em pacientes que sofrem com dor neuropática, essas perdas podem aparecer combinadas, separadas ou pode não aparecer em tudo ${ }^{48}$. No caso dos pacientes do estudo, há lesão principalmente das fibras de grande diâmetro (mielinizadas), demonstrada pelo número maior de testes anormais nos exames de sensibilidade vibratória e monofilamento; associação entre a escala de dor LANNS e o teste do monofilamento; e a própria escala de dor LANNS que as perguntas mais pontuadas pelos pacientes com dor neuropática identificada pela escala são as que avaliam fibras de grande diâmetro (perguntas 1 e 2).

O fato da escala de dor LANNS não ter sido testada em pacientes provenientes de atenção básica e utilizada para detectar características neuropáticas em dor mista (inflamatória e neuropática, presentes na mesma condição patológica) também pode justificar nossos dados que mostram que a maioria dos pacientes tem dor com características de neuropatia, porém possíveis mecanismos neuropáticos não foram identificados pela escala porque ela avalia com maiores pontuações fibras de grande diâmetro e os pacientes ainda não têm lesão nessas fibras, ou seja, ainda estão em uma fase inicial de lesão, onde os pacientes com pontuação < 12 na escala pontuaram mais a pergunta e o exame de sensibilidade que avalia fibra de pequeno diâmetro (pergunta 5 e exame de sensibilidade - alteração do limiar por estímulo de agulha).

Observa-se que a dor considerada como o quinto sinal vital, não tem sido investigada durante as consultas na atenção primária, e quando citada o tratamento não tem sido eficiente. A pesquisa mostra que esses pacientes tem dor com características neuropáticas, mesmo não sendo identificada com possíveis mecanismos neuropáticos pela escala de dor LANNS, devendo, portanto, ser investigada e tratada da melhor maneira possível durante as consultas na atenção básica. 


\section{CONCLUSÕES}

Nesse estudo a maioria da amostra é formada por pessoas do sexo feminino, sendo a média de idade de $51 \pm 6$ anos, de cor/etnia parda, estado civil casado, possui ensino fundamental. Em relação a ocupação a maior parcela do estudo é formada por donas de casa (30\%), seguido de pessoas que estão empregadas (29,5\%), autônomos (17,3\%) e desempregados (10,5\%). Os setores de atividade remunerada mais relatados foram: trabalhadores dos serviços, vendedores do comércio em lojas e mercados; e trabalhadores da produção de bens e serviços industriais. A maioria afirmou que o sustento da família vem do trabalho e não receber nenhum benefício do governo. A renda familiar total foi em média de $\mathrm{R} \$ 2225,74 \pm 1572,80$ reais; o número de pessoas que vivem da renda foi em média $4 \pm 2$ pessoas. A renda per capita foi em média $\mathrm{R} \$ 675,67 \pm 492,70$ reais.

A população do estudo tem dor e 93,64\% dos pacientes referem dor nos pés e/ou panturrilhas (mesmo não sendo a dor que mais incomoda), sendo que houve diferença estatística entre esse grupo com dor nos pés e/ou panturrilhas e o grupo de pessoas que não sentiam dor. A intensidade da dor foi de moderada a intensa, mais da metade sente dor ou durante a noite ou dia e noite e, para um percentual considerável de pessoas (47\%), a dor já incomodou a ponto de acordar. As características mais relatadas pelos pacientes foram: fadiga, câimbras, queimação, formigamento, dormência, alfinetada e/ou agulhada.

Nesse estudo encontramos uma parcela considerável de pacientes que no momento da pesquisa apresentava glicemia acima dos padrões toleráveis, o que mostra que devem ser realizadas ações específicas voltadas a esses pacientes para o controle adequado da glicemia e a maioria dos participantes tem o diagnóstico de diabetes há menos de 10 anos.

Em relação aos testes de função sensorial mais da metade dos pacientes do estudo (78\%) apresentou respostas preservadas e $22 \%$ dos pacientes tem PSP, ou seja, foram identificados com neuropatia diabética pois já apresentam perda da sensibilidade protetora plantar.

O exame para a avaliação da função sensorial que apresentou mais alteração foi o da sensibilidade vibratória, seguido pela sensação de pressão, sensibilidade dolorosa profunda, reflexo Aquileu e sensibilidade à temperatura.

Dos pacientes com dor considerada crônica e que tinham glicemia dentro dos padrões toleráveis mais da metade $(87,5 \%)$ apresentou dor no qual possíveis mecanismos neuropáticos não estariam contribuindo segundo a escala LANNS, 12,5\% apresentou dor no qual possíveis mecanismos neuropáticos estariam contribuindo para a dor do paciente. Desses últimos, a maioria teve o teste de monofilamento normal, sensibilidade dolorosa profunda normal, 
sensibilidade vibratória normal e exame de sensibilidade a temperatura normal. Todos apresentaram o reflexo de Aquileu normal e a maioria teve PSP descartada.

A maioria dos pacientes não tem dor com possíveis mecanismos neuropáticos de acordo com a escala de dor LANNS, nem alteração nos testes, porém apresenta sintomas característicos de dor neuropática que são: presença de dor nos pés e/ou panturrilhas de intensidade moderada a intensa; que aparece frequentemente ou continuamente; que costuma piorar noite ou dia e noite e as características mais frequentes são fadiga, câimbras, queimação, formigamento, dormência e alfinetada e/ou agulhada. O processo inflamatório sistêmico provocado pela hiperglicemia, resistência à insulina, perda da sinalização da insulina e/ou dislipidemia pode ser o que está contribuindo para a dor desses pacientes que não foram identificados com dor neuropática pela escala de dor LANNS. A dor nociceptiva e inflamatória são respostas protetoras do organismo, a hipótese levantada aqui é de que esses pacientes vêm sofrendo processos inflamatórios sucessivos, porém ainda não há dano suficiente para o paciente apresentar fenótipo de dor neuropática que possa ser detectado por instrumentos como a Escala de dor LANNS.

O Ministério da Saúde em seu caderno de atenção básica nº 36 específico para diabetes mellitus, preconiza que: toda pessoa com DM realize anualmente o exame dos pés, identificando fatores de risco para úlceras e amputação. A consulta de enfermagem deve incluir uma rotina sistemática de avaliação da sensibilidade protetora e da integridade dos pés, com vistas a prevenir danos, alguns aspectos da história do paciente também são essenciais para a identificação das pessoas de maior risco para ulceração nos pés. Nas consultas deve-se também questionar em relação à presença de sintomas neuropáticos positivos (dor em queimação ou em agulhada, sensação de choque) e negativos (dormência, sensação de pé morto), além da presença de sintomas vasculares, controle glicêmico e complicações. Após essa investigação inicial, o próximo passo é a inspeção dos pés, observando principalmente se os calçados utilizados são adequados. Após a inspeção, segue-se o exame físico minucioso que pode ser dividido em quatro etapas: avaliação da pele, avaliação musculoesquelética, avaliação vascular e avaliação neurológica (utilizando os testes para a avaliação sensorial) . $^{8}$

No Brasil não existem estudos como esse realizados na atenção primária, eles são importantes porque demonstram como estão os pacientes antes das complicações. A maioria dos diabéticos são atendidos na atenção primária e o objetivo do atendimento nesse nível de atenção é o tratamento e a prevenção de complicações como a ND.

A maior parte dos pacientes da pesquisa encontram-se em estágio inicial de lesão dos nervos somatossensoriais, condição demonstrada tanto pela resposta normal pela maioria da 
amostra dos testes de função sensorial, quanto pelo fato da maioria dos pacientes ainda não ter sido rastreados pela escala de dor LANNS, onde possíveis mecanismos neuropáticos estariam contribuindo para a dor do paciente. Se não houver o controle glicêmico e de outras comorbidades como as dislipidemias, a tendência é a cronificação dessa lesão, estendendo-se às fibras de grande diâmetro, levando a ND e a dor neuropática.

Esse estudo abre possibilidades para uma nova abordagem em relação a promoção, prevenção e tratamento da população com o diagnóstico de DM. A consulta de enfermagem está preconizada no atendimento dos pacientes diabéticos dentro da atenção primária ${ }^{8}$. A maioria desses pacientes ainda não tem lesões detectadas pelos exames de função sensorial, sendo essencial o planejamento da assistência voltado para a educação em saúde, com ações que melhorem o controle glicêmico/metabólico dessa população, cuidado com os pés, prevenindo assim o aparecimento de úlceras que podem levar a amputação. Em relação a dor que esses pacientes sentem, os que foram identificados com dor com prováveis mecanismos neuropáticos devem ser acompanhados e direcionados para o tratamento adequado dessa dor. Os pacientes no qual prováveis mecanismos neuropáticos não estariam contribuindo para a dor, devem ser avaliados quando a presença de inflamação e serem direcionados para um tratamento adequado e específico.

Temos como limitações do estudo a escala de dor LANSS que foi elaborada para ambiente hospitalar e para todos os tipos de dor neuropática, o fato da escala detectar principalmente pacientes com lesões em fibras de grande diâmetro pode ter reduzido sua especificidade para a detecção de dor neuropática em pacientes na atenção primária, que no caso do estudo apresentaram respostas em questões que avaliam fibras de pequeno diâmetro. Seria recomentado portanto o uso de escalas que identifiquem dor neuropática previamente utilizadas na atenção primária. 


\section{REFERÊNCIAS}

1 Boulton AJ, Vinik AI, Arezzo JC, Bril V, Feldman EL, Freeman R et al. Diabetic neuropathies: a statement by the American Diabetes Association. Diabetes Care 2005 Apr;28(4):956-62.

2 Yagihashi S, Yamagishi S, Wada R. Pathology and pathogenetic mechanisms of diabetic neuropathy: correlation with clinical signs and symptoms. Diabetes Res Clin Pract 2007 Sep;77 Suppl 1:184-9.

3 Abbott CA, Malik RA, van Ross ER, Kulkarni J, Boulton AJ. Prevalence and Characteristics of Painful Diabetic Neuropathy in a Large Community-Based Diabetic Population in the U.K. Diabetes Care. 2011 Oct;34(10):2220-4.

4 Deli G, Bosnyak E, Pusch G, Komoly S, Feher G. Diabetic neuropathies: diagnosis and management. Neuroendocrinology 2013;98(4):267-80.

5 Tesfaye S, Vileikyte L, Rayman G, Sindrup SH, Perkins BA, Baconja M, Vinik AI, Boulton AJ; Toronto Expert Panel on Diabetic Neuropathy. Painful diabetic peripheral neuropathy: consensus recommedations on diagnosis assessment and management. Diabetes Metab Res Rev. 2011 Oct;27(7):629-38.

6 International Association for the Study of Pain. As polineuropatias dolorosas [acesso em 02 jan 2016]. Disponível em: http://iasp.files.cmsplus.com/AM/Images/GYAP/Neuropathic/painful_polyneuro athypt.pdf

7 Jimenez-Cohl $\mathrm{P}^{1}$, Grekin C, Leyton C, Vargas C, Villaseca R. Thermal Threshold: Research Study on Small Fiber Dysfunction in Distal Diabetic Polyneuropathy. J Diabetes Sci Technol. 2012 Jan 1;6(1):177-83.

8 Brasil. Ministério da Saúde. Secretaria de atenção à Saúde. Departamento de Atenção Básica. Estratégias para o cuidado da pessoa com doença crônica: diabetes mellitus. [caderno na internet] Brasília: Ministério da Saúde, 2013. [acesso em 02 jan 2015]. Disponível em: http://189.28.128.100/dab/docs/portaldab/publicacoes/caderno_36.pdf

9 Landowski LM, Dyck PJ, Engelstad J, Taylor BV. Axonopathy in peripheral neuropathies: Mechanisms and therapeutic approaches for regeneration. J Chem Neuroanat. 2016 May 2.

10 Mendell JR, Sahenk Z. Clinical practice. Painful sensory neuropathy. N Engl J Med. 2003 Mar 27;348(13):1243-55.

11 Tesfaye S, Boulton AJ, Dyck PJ, Freeman R, Horowitz M, Kempler P, Lauria G, Malik RA, Spallone V, Vinik A, Bernardi L, Valensi P; Toronto Diabetic Neuropathy Expert Group. Diabetic Neuropathies: Update on Definitions, Diagnostic Criteria, Estimation of Severity, and Treatments. Diabetes Care 2010 Oct; 33(10):2285-93. 
12 Singh R, Kishore L, Kaur N. Diabetic peripheral neuropathy: Current perspective and future directions. Pharmacol Res. 2014 Feb;80:21-35.

13 Woolf CJ. What is this thing called pain? J Clin Invest. 2010 Nov;120(11):3742-4.

14 Duncan BB, Schmidt MI, Pankow JS, Ballantyne CM, Couper D, Vigo A, Hoogeveen R, Folsom AR, Heiss G; Atherosclerosis Risk in Communities Study. Low-Grade Systemic Inflammation and the Development of Type 2 Diabetes: the atherosclerosis risk in communities study. Diabetes. 2003 Jul;52(7):1799-805.

15 Shoelson SE, Lee J, Goldfine AB. Inflammation and insulin resistance. J Clin Invest. 2006 Jul;116(7):1793-801.

16 Herder C, Bongaerts BW, Rathmann W, Heier M, Kowall B, Koenig W, et al. Association of Subclinical Inflammation With Polyneuropathy in the Older Population: KORA F4 study. Diabetes Care. 2013 Nov;36(11):3663-70.

17 Boulton AJ, Armstrong DG, Albert SF, Frykberg RG, Hellman R, Kirkman MS et al American Diabetes Association. Comprehensive foot examination and risk assesment: a report of the task force of the foot care interest group of the American Diabetes Association, with endorsement by the American Association of Clinical Endocrinologists. Diabetes Care. 2008 Aug;31(8):1679-85.

18 Partanen J, Niskanen L, Lehtinen J, Mervaala E, Siitonen O, Uusitupa M. Natural history of peripheral neuropathy in patients with non insulindependent diabetes mellitus. N Engl J Med. 1995 Jul 13;333(2):89-94.

19 Backonja MM, Attal N, Baron R, Bouhassira D, Drangholt M, Dyck PJ et al. Value of quantitative sensory testing in neurological and pain disorders: NeuPSIG consensus. Pain. 2013 Sep;154(9):1807-19.

20 International Association for the Study of Pain. Halting the March of Painful Diabetic Neuropathy. Pain: clinical updates [periódicos na internet] 2015 Apr [acesso em 02 jan 2016];23(2):1-8. [acesso em 02 jan 2016]. Disponível em: http://iasp.files.cmsplus.com/Content/ContentFolders/Publications2/PainClinicalUpdates/Archives/pcu_vol2 3_no2_apri12015_1428006215952_2.pdf.

21 Costigan M, Scholz J, Woolf CJ. Neuropathic Pain: A Maladaptive Response of the Nervous System to Damage. Annu Rev Neurosci. 2009;32:1-32.

22 Tesfaye S, Vileikyte L, Rayman G, Sindrup SH, Perkins BA, Baconja M, Vinik AI, Boulton AJ; Toronto Expert Panel on Diabetic Neuropathy. Painful diabetic peripheral neuropathy: consensus recommendations on diagnosis, assessment and management. Diabetes Metab Res Rev. 2011 Oct;27(7):629-38.

23 Freeman R, Baron R, Bouhassira D, Cabrera J, Emir B. Sensory profiles of patients with neuropathic pain based on the neuropathic pain symptoms and signs. Pain. 2014 Feb;155(2):367-76. 
24 Haddad N. Metodologia de estudos em ciências da saúde. 1st ed. São Paulo: Roca 2004.

25 Bolfarine H; Bussab W. Elementos de amostragem. Editora Edgard Blücher, 2005.

26 Brasil. Ministério da Saúde. Secretaria de atenção à saúde. Portaria $N^{\circ} 1.083$, de 2 de outubro de 2012. Aprova o Protocolo Clínico e Diretrizes Terapêuticas da Dor Crônica. [Portaria na Internet] Diário Oficial da União 03 out 2012. [Acesso em: 29 jan. 2014]. Disponível em: http://www.brasilsus.com.br/legislacoes/sas/115462-1083.html?tmpl=....

27 International Association for the Study of Pain. Chronic Pain Conditions Incorporated Into Beta Version of ICD11 [acesso em 02 jan 2016]. Disponível em: http://www.iasppain.org/PublicationsNews/IASPNewsletterArticle.aspx?ItemNumber=3 331.

28 Bennett M. The LANSS Pain Scale: the Leeds assessment of neuropathic symptoms and signs. Pain. 2001;92(1-2):147-57.

29 Schestatsky P, Félix-Torres V, Chaves ML, Câmara-Ehlers B, Mucenic T, Caumo W, Nascimento O, Bennett MI. Brazilian Portuguese validation of theLeeds assessment of neuropathic symptoms and signs for patients with chronic pain. Pain Med. 2011;12(10):1544-50.

30 Weinstein S, Sersen EA. Tactual sensitivity as a function handedness and laterality. J Comp Physiol 1961; 54:665-669. 25 Semmes J. Cambridge Harvard University press, 462, 1960.

31 Malerbi DA, Franco LJ. Multicenter Study of the Prevalence of Diabetes Mellitus and Impaired Glucose Tolerance in the Urban Brazilian Population Aged 30-69 yr. The Brazilian Cooperative Group on the Study of Diabetes Prevalence. Diabetes Care. 1992 Nov;15(11):1509-16.

32 Torquato MT1, Montenegro Júnior RM, Viana LA, de Souza RA, Lanna CM, Lucas JC, Bidurin C, Foss MC. Prevalence of diabetes mellitus and impaired glucose tolerance in the urban population aged 30-69 years in Ribeirão Preto (São Paulo), Brazil. Sao Paulo Med J. 2003 Nov 6;121(6):224-30.

33 International Diabetes Federation. IDF Diabetes Atlas. Sixth Edition. [acesso em 02 jun 2015]. Disponível em: www.idf.org/diabetesatlas.

34 Jin Y, Kanamori A, Ito S, Matoba K, Miyakawa M, Kaneshige H et al. Cross-sectional survey of diabetic neuropathy in Kanagawa and clinical significance of a touch test using tissue paper. J Diabetes Investig. 2012 Jun 6;3(3):252-8.

35 Brasília. Governo de Brasília. Companhia de Planejamento do Distrito Federal. Secretaria de Orçamento, Planejamento e Gestão. Pesquisa Distrital por Amostra de Domicílio Ceilândia - PDAD. [pesquisa na internet] Brasília: Companhia de Planejamento do Distrito Federal, 2015. [acesso em 01 jan 2016] Disponível em: 
http://www.codeplan.df.gov.br/images/CODEPLAN/PDF/pesquisa_socioeconomica/pda d/2015/PDAD_Ceilandia_2015.pdf.

36 Mackenbach JP. Can we reduce health inequalities? An analysis of the English strategy (1997 - 2010). J Epidemiol Community Health. 2011 Jul;65(7):568-75.

37 Alonso ED. Desigualdades sociales y diabetes mellitus. Revista Cubana de Endocrinología 2013;24(2):200-213.

38 Sommer I, Griebler U, Mahlknecht P, Thaler K, Bouskill K, Gartlehner G, Mendis S. Socioeconomic inequalities in non-communicable diseases and their risk factors: an overview of systematic reviews. BMC Public Health. 2015 Sep 18;15:914.

39 Agardh EE, Sidorchuk A, Hallqvist J, Ljung R, Peterson S, Moradi T, Allebeck P. Burden of type 2 diabetes attributed to lower educational levels in Sweden. Popul Health Metr. 2011 Dec 16;9:60.

40 Mackenbach JP, Bakker MJ; European Network on Interventions and Policies to Reduce Inequalities in Health. Tackling socioeconomic inequalities in health: analysis of European experiences. Lancet. 2003 Oct 25;362(9393):1409-14.

41 Bouhassira D, Attal N, Alchaar H et. al. Comparison of pain syndromes associated with nervous or somatic lesions and development of a new neuropathic pain diagnostic questionnaire (DN4). Pain. 2005; 114:29-36.

42 Resende MAC, Nascimento OJM, Rios AAS, Quintanilha G, Ceballos LES, Araújo FP. Perfil da dor neuropática: a propósito do exame neurológico mínimo de 33 pacientes. Rev Bras Anestesiol. 2010; 60(2): 144-153.

43 Santos DR, Fornel ACG, Bezerra AF, Duarte J, Gervásio SMD. Clinical topographic analysis of neuropathic pain in patients admitted in a center of multidisciplinary treatment. Rev Dor. 2014; out-dez;15(4):267-70.

44 Brasília. Secretaria de Estado de Saúde do Distrito Federal. Brasília Saudável. Fortalecimento da atenção primária à saúde do Distrito Federal. [caderno na internet] Brasília: Secretaria de Estado de Saúde do Distrito Federal, 2016. [acesso em 30 de jun 2016]. Disponível em: http://www.coren-df.gov.br/site/wpcontent/uploads/2016/06/BRASILIA_SAUDAVEL_DOCUMENTO_REFERENCIAL.p df.

45 Boulton AJ, Malik RA, Arezzo JC, Sosenko JM. Diabetic Somatic Neuropathies. Diabetes Care. 2004 Jun;27(6):1458-86.

46 Smieja M, Hunt DL, Edelman D, Etchells E, Cornuz J, Simel DL. Clinical examination for the detection of protective sensation in the feet of diabetic patients. International Cooperative Group for Clinical Examination Research. J Gen Intern Med. 1999 Jul;14(7):418-24. 
47 Themistocleous AC, Ramirez JD, Shillo PR, Lees JG, Selvarajah D, Orengo C, Tesfaye S, Rice AS, Bennett DL. The Pain in Neuropathy Study (PiNS): a cross-sectional observational study determining the somatosensory phenotype of painful and painless diabetic neuropathy. Pain. 2016 May;157(5):1132-45. 


\section{APÊNDICES}

\section{Apêndice 1}

Tabela para determinação do tamanho amostral por erro de estimação de proporções (considerando uma população de tamanho de 9000 indivíduos e $\alpha=5 \%$ ).

\begin{tabular}{cc}
\hline Erro máximo & Tam. Amostra \\
\hline 0,01 & 3862 \\
0,02 & 1424 \\
0,03 & 694 \\
0,04 & 404 \\
0,05 & 263 \\
$\mathbf{0 , 0 6}$ & $\mathbf{1 8 4}$ \\
0,07 & 136 \\
0,08 & 104 \\
0,09 & 83 \\
0,10 & 67 \\
0,15 & 30 \\
0,20 & 17 \\
0,25 & 11 \\
\hline
\end{tabular}




\section{Apêndice 2}

\section{Termo de Consentimento Livre e Esclarecido - TCLE}

O (a) Senhor (a) está sendo convidado (a) a participar do projeto: "Descrição do perfil sócio demográfico, caracterização e identificação da dor com características neuropáticas em indivíduos com o diagnóstico de diabetes mellitus tipo 2 atendidos na atenção primária”.

O nosso objetivo é: descrever o perfil sócio demográfico, identificar e caracterizar a dor com características neuropáticas em indivíduos com o diagnóstico de diabetes mellitus tipo 2 atendidos na atenção primária.

O (a) senhor (a) receberá todos os esclarecimentos necessários antes e no decorrer da pesquisa e lhe asseguramos que seu nome não aparecerá sendo mantido o mais rigoroso sigilo através da omissão total de quaisquer informações que permitam identificá-lo (a)

A sua participação será através de uma avaliação clínica dos pés e entrevista que ocorrerão no Centro de Saúde $\mathrm{n}^{\circ} 02, \mathrm{n}^{\circ} 03, \mathrm{n}^{\circ} 05, \mathrm{n}^{\circ} 06, \mathrm{n}^{\circ} 07, \mathrm{n}^{\circ} 08, \mathrm{n}^{\circ} 09, \mathrm{n}^{\circ} 11$ e $\mathrm{n}^{\circ} 12$ de Ceilândia na data combinada, com um tempo estimado 1 hora. Não existe obrigatoriamente, um tempo pré-determinado, para a avaliação completa (exame dos pés e entrevista). Será respeitado o tempo de cada um para respondê-lo. Informamos que o (a) Senhor (a) pode se recusar a permitir que seja realizada a avaliação clínica de seus pés e também se recusar a responder qualquer questão que lhe traga constrangimento, podendo desistir de participar da pesquisa em qualquer momento sem nenhum prejuízo para a senhor (a).

Os resultados da pesquisa serão divulgados aqui no Centro de Saúde no 8 e na Regional de Saúde de Ceilândia e na Instituição Faculdade UnB Ceilândia podendo ser publicados posteriormente. Os dados e materiais utilizados na pesquisa ficarão sobre a guarda do pesquisador.

Se o Senhor (a) tiver qualquer dúvida em relação à pesquisa, por favor telefone para: Prof. ${ }^{a}$ Dr $^{a}$ Mani Indiana Funez, na instituição Faculdade UnB Ceilândia telefone: (61) 96686608, no horário: 08-17h00.

Este projeto foi Aprovado pelo Comitê de Ética em Pesquisa da SES/DF. As dúvidas com relação à assinatura do TCLE ou os direitos do sujeito da pesquisa podem ser obtidas através do telefone: (61) 3325-4955.

Este documento foi elaborado em duas vias, uma ficará com o pesquisador responsável e a outra com o sujeito da pesquisa.

Nome / assinatura:

Pesquisador Responsável

Nome e assinatura:

Brasília, de de 


\section{ANEXOS}

Anexo 1 - Aprovação do Comitê de Ética e Pesquisa com Seres Humanos

\section{- DADOS DA VERSÄO DO PROJETO DE PESQUISA}

Título da Pesquisa: Dor relacionada à polineuropatia diabética: caracterização, perfil epidemiológico, impacto e perfil evolutivo em indivíduos portadores de diabetes mellitus tipo 2 Pesquisador Responsável: Mani Indiana Funez

Area Temática:

Versão: 1

CAAE: 30955914.3 .0000 .5553

Submetido em: 08/05/2014

Instituiçäo Proponente: Hospital Regional de Ceilândia

Situação da Versão do Projeto: Aprovado

Localização atual da Versão do Projeto: Secretaria de Estado de Saúde do Distrito Federal - FEPECS/ SES/ DF

Patrocinador Principal: Financiamento Próprio

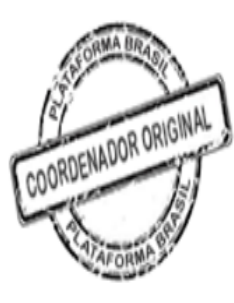




\section{Anexo 2}

ESCALA DE DOR LANNS (Adaptada ao Português do Brasil por Schestatskyet al., 2011), PORTARIA N ${ }^{\circ} 1.083$, DE 2 DE OUTUBRO DE 2012

Nome: Data:

Esta escala de dor ajuda a determinar como os nervos que carregam a informação de dor estão funcionando. É importante obter estetipo de informação, pois ela pode ajudá-lo na escolha de um tratamento específico para o seu tipo de dor.

\section{A. QUESTIONÁRIO DE DOR}

- Pense na dor que você vem sentindo na última semana.

- Por favor, diga se qualquer uma das características abaixo se aplica à sua dor. Responda apenas SIM ou NÃO.

1) A sua dor se parece com uma sensação estranha e desagradável na pele? Palavras como "agulhadas", "choques elétricos" e "formigamento" são as que melhor descrevem estas sensações.

a) $\mathrm{NÃO}$

- Minha dor não se parece com isso

[0]

b) SIM - $\mathrm{Eu}$ tenho este tipo de sensação com frequência. [5]

2) A sua dor faz com que a cor da pele dolorida mude de cor? Palavras como "manchada" ou "avermelhada ou rosada" descrevem a aparência da sua pele.

a) NÃO - Minha dor não afeta a cor da minha pele.. [0]

b) SIM - Eu percebi que a dor faz com que minha pele mude de cor. [5]

3) A sua dor faz com a pele afetada fique sensível ao toque? [A ocorrência de] Sensações desagradáveis ou dolorosas ao toque leve ou mesmo ao toque da roupa ao vestir-se descrevem esta sensibilidade anormal. -

a) NÃO - Minha dor não faz com que minha pele fique mais sensível...........................................[0]

b) SIM - Minha pele é mais sensível ao toque nesta área........ [3]

4) A sua dor inicia de repente ou em crises, sem nenhuma razão aparente, quando você está parado, sem fazer nenhum movimento? Palavras como "choques elétricos", "dor em pontada" ou "dor explosiva" descrevem estas sensações.

a) NÃO - Minha dor não se comporta desta forma 
b) SIM - $\mathrm{Eu}$ tenho estas sensações com muita frequência.

5) A sua dor faz com que a temperatura da sua pele na área dolorida mude? Palavras como "calor" e "queimação" descrevem estas sensações.

a) $\mathrm{NÃO} \quad-\quad \mathrm{Eu}$ não tenho este tipo de sensação......................................................................... $[0]$

b) $\quad$ SIM $\quad-\quad \mathrm{Eu} \quad$ tenho $\quad$ estas $\quad$ sensações $\quad$ com frequência................................................................. [1]

B. EXAME DA SENSIBILIDADE (preenchido pelo profissional de saúde) A sensibilidade da pele pode ser examinada comparando-se a área dolorida com a área contralateral ou nas áreas adjacentes não doloridas avaliando a presença de alodinia e alteração do limiar de sensação ao estímulo da agulha (LSA).

\section{6) ALODINIA}

Examine a resposta ao toque leve com algodão sobre a área não dolorida e, a seguir, ao toque da área dolorida. Caso sensações normais forem percebidas no lado não dolorido e, ao contrário, se dor ou sensações desagradáveis (sensação tipo "picada" ou "latejante") forem percebidas na área afetada, então a alodinia está presente.

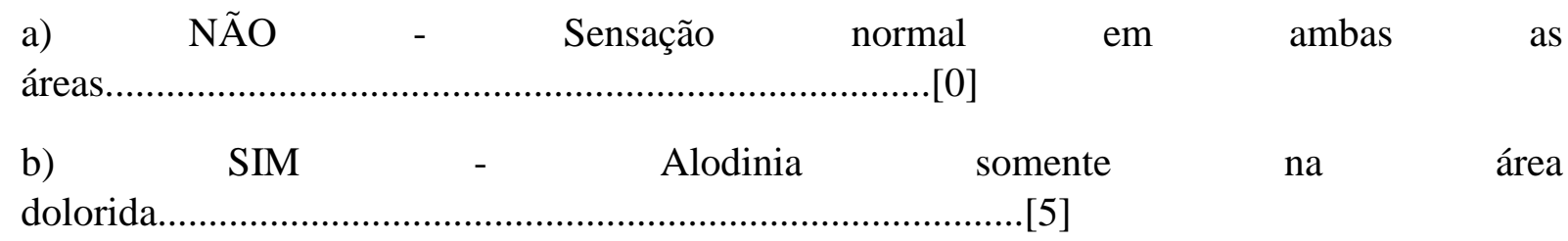

\section{7) ALTERAÇÃO DO LIMIAR POR ESTÍMULO DE AGULHA}

a) Determine o limiar por estímulo de agulha pela comparação da resposta a uma agulha de espessura 23 (cor azul) conectada a uma seringa de $2 \mathrm{ml}$ - sem a parte interna - suavemente colocada nas áreas doloridas da pele e depois nas não doloridas.

b) Caso uma sensação de agulhada normal for sentida na área da pele não dolorida, mas uma sensação diferente for sentida na área dolorida como, por exemplo, "nenhuma sensação" ou "somente sensação de toque" (LSA aumentado) ou "dor muito intensa" (LSA diminuído), isso significa que há um LSA alterado.

c) Caso a sensação de agulhada não for percebida em nenhuma área, conecte a parte interna da seringa à agulha para aumentar o peso e repita a manobra.

a) NÃO - $\quad$ Sensação igual em ambas as áreas. [0]

b) SIM - Limiar por estímulo de agulha alterado no lado dolorido. [3]

\section{ESCORE:}

Some os valores entre parênteses nos achados descritivos e de exame da sensibilidade para obter um escore global. ESCORE TOTAL (máximo 24) 
Se o escore for inferior a 12, [são improváveis de] estejam contribuindo para a dor do paciente. Se o escore for igual ou superior a 12, provavelmente mecanismos neuropáticos estejam contribuindo para a dor do paciente. 

